\title{
Cotransport of Hydroxyapatite Nanoparticles and Hematite Colloids in Saturated Porous Media: Mechanistic Insights from Mathematical Modeling and Phosphate Oxygen Isotope Fractionation
}

\author{
Dengjun Wang, Yan Jin*, and Deb P. Jaisi* \\ Department of Plant and Soil Sciences, University of Delaware, Newark, DE 19716, United States \\ *Corresponding Authors \\ Dr. Deb P. Jaisi \\ E-mail: jaisi@udel.edu; Tel.: +1 302831 1376; Fax: +1 3028310605 \\ And \\ Dr. Yan Jin \\ E-mail: yjin@udel.edu; Tel.: +1 302831 6962; Fax: +1 3028310605
}

Revised for

Journal of Contaminant Hydrology

September6, 2015 
Abbreviations

\begin{tabular}{ll} 
ADE & Advection-dispersion equation \\
BET & Brunauer-Emmett-Teller \\
BTC & Breakthrough curve \\
CFT & Classical filtration theory \\
DLS & Dynamic light scattering \\
DLVO & Derjaguin-Landau-Verwey-Overbeek \\
EDX & Energy-dispersive X-ray \\
EM & Electrophoretic mobility \\
ENP & Engineered nanoparticle \\
FTIR & Fourier transform infrared \\
HANP & Hydroxyapatite nanoparticle \\
IEP & Isoelectric point \\
IS & Ionic strength \\
NOM & Natural organic matter \\
PV & Pore volume \\
RP & Retention profile \\
SEM & Scanning electron microscope \\
SSA & Specific surface area \\
TEM & Transmission electron microscope \\
VSMOW & Vienna Standard Mean Ocean Water \\
XRD & X-ray diffraction \\
$\boldsymbol{\delta}^{18}$ OP & Phosphate oxygen isotope ratio \\
$\boldsymbol{q}$ & Darcy velocity \\
$\zeta$-potential & Zeta potential \\
\hline
\end{tabular}




\section{Abstract}

The fate and transport of individual type of engineered nanoparticles (ENPs) in porous

3 media have been studied intensively and the corresponding mechanisms controlling ENPs

4 transport and deposition are well-documented. However,investigations regarding the mobility of

5 ENPs in the concurrent presence of another mobile colloidal phase such as naturally occurring

6 colloids (colloid-mediated transport of ENPs) are largely lacking. Here, we investigatedthe

7 cotransport and retention of engineered hydroxyapatite nanoparticles (HANPs) with naturally

8 occurring hematite colloids in water-saturated sand columns under environmentally relevant

9 transport conditions, i.e., $\mathrm{pH}$, ionic strength (IS), and flow rate. Particularly, phosphate oxygen

10 isotope fractionation of HANPs during cotransport was explored at various ISs and flow rates to

11 examine the mechanisms controlling the isotope fractionation of HANPs in abiotic transport

12 processes (physical transport).

13 During cotransport, greater mobility of both HANPs and hematiteoccurred at higher $\mathrm{pHs}$

14 and flow rates, but at lower ISs. Intriguingly, the mobility of both HANPs and hematite was

15 substantially lower during cotransport than the individual transport of either, attributed primarily

16 to greater homo- and hetero-aggregation when both particles are copresent in the suspension. The

17 shapes of breakthrough curves (BTCs) and retention profiles (RPs) during cotransport forboth

18 particlesevolved from blocking to ripening with time and from flat to hyperexponential with

19 depth, respectively, in response to decreases in $\mathrm{pH}$ and flow rate, and increases in IS. The

20 blocking BTCs and RPs that are flat or hyperexponential can be well-approximated by a one-site

21 kinetic attachment model. Conversely, a ripening model that incorporates attractive particle-

22 particle interaction has to be employed to capture the ripening BTCs that are impacted by

23 particle aggregation during cotransport. 
A small phosphate oxygen isotope fractionation $(\leq 2 \%)$ occurred among

25 HANPspopulations during cotransport responding to IS and flow rate changes. This fractionation

26 is most likely a result of hetero-aggregation between hematite and HANPs that favors light

27 phosphate isotopes $\left(\mathrm{P}^{16} \mathrm{O}_{4}\right)$. This interpretation is furthersupported by the increase in

28 isotopefractionation at higher ISs (i.e., greateraggregation). However, the fractionation was

29 progressively erased by decreasing flow rate, ascribedto the reduced mass transfer of HANPs

30 between theinfluent and effluent. Together our findings suggest that the cotransport and

31 retentionof HANPs and hematite colloidsarehighly sensitive to the considered physicochemical

32 factors, and isotope tracing could serve as a promising tool to identify the sources and transport

33 of phosphate-based NPs in complex subsurface environments due toinsignificant transport-

34 related isotope fractionation.

36 Keywords:Hydroxyapatite nanoparticles; Hematite colloids; Porous media; Cotransport;

37 Mathematical modeling; Phosphate oxygen isotope fractionation

\section{Introduction}

The past decade has witnessed the rapid development of nanotechnology (Roco and 41 Bainbridge, 2013), which is aimed at using materials with specific and novel propertiesand 42 functions in the length scale of 1-100 nm (National Nanotechnology Initiative, NNI). Nowadays, 43 there are >3000 nanotechnology-based consumer products in the market worldwide (Nanowerk 44 Nanomaterial Database). Being one of the most important inorganic nanoparticles (NPs), 45 hydroxyapatite NPs (HANPs, $\left.\mathrm{Ca}_{10}\left(\mathrm{PO}_{4}\right)_{6}(\mathrm{OH})_{2}\right)$ have been employedin the medical fieldsuch as 46 bone tissue engineering applications, intracellular drug delivery, and gene delivery because of 
47 theirexcellent biocompatibility and bioactivity (Balasundaram et al., 2006; Chen et al., 2011; Zhu 48 et al., 2004). Furthermore, attributable to their nanoscale dimensions, large specific surface area 49 (SSA), and high reactivity, HANPs have been extensively used as an effective absorbent to 50 sequester metals and radionuclides in contaminated soils, sediments, and groundwater, in-situ or 51 ex-situ(Chen et al., 2010; Handley-Sidhu et al., 2012; Zhang et al., 2010). Recently, HANPs have 52 been advocated as a promising phosphorus (P) nanofertilizer (Liu and Lai, 2014; Montalvo et al., 53 2015; Wang et al., 2015a). For example, through a greenhouse potexperiment, Liu and Lal (2014) 54 found that application of HANPs enhanced the growth rate and seed yield of soybean (Glycine $55 \max$ ) by $33 \%$ and $20 \%$, respectively, compared to those fertilized by a regular solid P fertilizer $56\left(\mathrm{Ca}\left(\mathrm{H}_{2} \mathrm{PO}_{4}\right)_{2}\right)$. This is likely due to HANPs' higher mobility than their bulk counterparts 57 and/orlarger reactive surface area allowing greater dissolution and release of $\mathrm{P}$, thereby reaching 58 the rhizosphere and subsequently nurturing crops in a timely fashion. Increasing use of HANPs 59 for medical, environmental, and agronomic advantages will likely result in an unknown spread of 60 HANPs and released $\mathrm{P}$ in the subsurface environments.

61 A more complete understanding of the fate and transport of HANPs in the subsurface 62 environments will guide the selection of the best-suited strategy for in-situ remediation of 63 contaminated sites, and optimization of nanofertilizer applications in agricultural soils. Generally, 64 the transport and deposition of NPs in saturated porous media are influenced by the interplay of 65 physicochemical properties of particle and collector surfaces, and solution chemistry and 66 hydrodynamics of the system (e.g., Elimelech et al., 1995;Grolimund et al., 1998; Harter et al., 67 2000; Petosa et al., 2010; Schijven and Hassanizadeh, 2000; Wang et al., 2015b). Such factors as $68 \mathrm{pH}$, ionic strength (IS), and flow rate have been documented to have significant impacts on the 69 transport behavior of NPs (Chen et al., 2012; Chowdhury et al., 2011; Jiang et al., 2012; Li et al., 
70 2008; Wang et al., 2014a; 2015b). Nevertheless, an overwhelming majority of the existing

71 studies are limited to the transport of a single type of NPs in porous media. Few studies have

72 attempted to quantify the mobility of NPs in the copresence of another mobile colloidal phase

73 such as naturally occurring colloids, which have long been recognized as an important vector for

74 transport of both nutrients (Sims et al., 1998) and contaminants (e.g., metals, radionuclides, and

75 organic pollutants) in the subsurface(Cheng and Saiers, 2015; McCarthy and Zachara, 1989;

76 Shen et al., 2015). Iron oxides such as ferrihydrite, goethite, and hematite occur ubiquitously in

77 the subsurface (White and Brantley, 1995), and their mobile colloidal phase is known to play

78 critical roles in the fate, transport, bioavailability, and biogeochemical cycling of $\mathrm{P}$ including

79 HANPs due to their high sorption capacity toward P (Frossard et al., 1995; Stumm and

80 Sulzberger, 1991; van der Zee et al., 2003; Waychunas et al., 2005). It is therefore anticipated

81 that the mobility of HANPs in the subsurface is, in part, controlled by the presence of mobile

82 iron oxide colloids.Particularly, we recently demonstrated that transport and retentionof HANPs

83 werelargely influenced by mobile goethite NPs in response to variability in $\mathrm{pH}$, and type and

84 concentration of natural organic matter (NOM) in saturated porous media (Wang et al., 2015a).

85 However, the effects of other environmentally significant conditions,particularly ionic strength

86 and flow rate on the cotransport of HANPs and naturally occurring iron oxidecolloids are 87 nonexistent.

88 The last decade has also witnessed the burgeoning application of stable oxygen isotope

89 technique in tracing the sources and identifying the biogeochemical cycling of phosphate in

90 natural environments (Blake et al., 1997; Jaisi and Blake, 2014; Joshi et al., 2015; Paytan et al.,

91 2002). This is because orthophosphate $\left(\mathrm{PO}_{4}{ }^{3-}\right)$ is cycled primarily via biologically-mediated

92 reactions and the presence of enzymecauses changesin isotopic composition (Blake et al., 1997; 
93 Liang and Blake, 2006, 2009; Paytan et al., 2002; Stout et al., 2014). Interestingly, in abiotic

94 systems, oxygen isotope exchange is insignificant between phosphate and ambient water at low

95 temperature $\left(<80^{\circ} \mathrm{C}\right)$ and near-neutral $\mathrm{pH}$ conditions (Jaisi et al., 2010; Lecuyer et al., 1999; $\mathrm{Li}$

96 and Jaisi, 2015). More extensive application of oxygen isotope ratios in phosphate $\left(\delta^{18} \mathrm{O}_{\mathrm{P}}\right)$ as a

97 biogeochemical tracer of $\mathrm{P}$ sources and cycles, however, relies on a more complete

98 understanding of all processes and reactions that could (or not) lead to changes of isotopic

99 compositions as well as fractionation factors for particular reactions or processes. To date, there

100 is just one studyaimed at elucidating the isotope effects during phosphate transport in the

101 subsurface environments (Jaisi, 2013), thus limits our ability to better predict the variability of

$102 \delta^{18} \mathrm{O}_{\mathrm{P}}$ values between subsurface soils and pore-water. Jaisi (2013) found that oxygen isotope

103 exchange of dissolved phosphate ion between theeffluent and influent was $\sim 1.3 \%$ with

104 isotopically-lighter phosphate $\left(\mathrm{P}^{16} \mathrm{O}_{4}\right)$ preferentially retained in the column in the early stage of

105 transport, and this isotopic fractionation became negligible as more phosphate passed through the

106 column due to the efficient exchange between aqueous and sorbed phosphate ions over time.

107 However, the physical and thermodynamic properties of NPs are different from ions, and the

108 extent of isotope effects of NPs during transport is therefore expected to be different from those

109 of ions (Steefel and Van Cappellen, 1990). To accurately trace the sources and identify the

110 biogeochemical processes of HANPs in the subsurface environments, it is critical to elucidate the 111 isotope effects of HANPs during transport.

The goal of this research was to develop a better understanding of the fate, transport, and isotope fractionation of HANPs in the copresence of naturally occurring iron oxide (hematite) colloids in saturated porous media. Our specific objectives were to (i) determine the mechanisms controlling cotransport and retention of HANPs and hematite colloids under environmentally 
116 relevant transport conditions, i.e., $\mathrm{pH}$, IS, and flow rate; and (ii) elucidate the roles of IS and

117 flow rate on phosphate oxygen isotope fractionation among HANPs populations during cotransport.

\section{Materials and Methods}

\subsection{HANPs and hematite colloids}

HANPs (purity >99.9\%) were purchased from Nanjing Emperor Nanomaterial Co. Ltd.,

China. The physicochemicalproperties of the HANPs have been well-

characterizedpreviously(Wang et al., 2012a; 2015a). Briefly, the HANPs are single-phased pure hydroxyapatite mineral and display a rod morphology with mean dimensions of $20 \mathrm{~nm}$ wide and $100 \mathrm{~nm}$ long. The Ca/P molar ratio and SSA of HANPs are 1.65 and $154 \mathrm{~m}^{2} \mathrm{~g}^{-1}\left(\mathrm{~N}_{2}-\mathrm{BET}\right.$ method), respectively. The hematite colloids were synthesized following the method of Schwertmann and Cornell (2000). Shortly, $300 \mathrm{~mL}$ of $1 \mathrm{M} \mathrm{KOH}$ was added to $500 \mathrm{~mL}$ of $0.2 \mathrm{M}$ $\mathrm{Fe}\left(\mathrm{NO}_{3}\right)_{3}$ while stirring. Fifty $\mathrm{mL}$ of $1 \mathrm{M} \mathrm{NaHCO}_{3}$ was thenadded to the mixture and the resulting suspension was held in a closed glass flask at $90{ }^{\circ} \mathrm{C}$ for $48 \mathrm{~h}$. The synthesized hematite colloids were separated from residual reagents through a DI water wash-centrifugation procedure, freeze-dried, ground with mortar and pestle, and passed through a No. 70 standard sieve $(0.212$ mm opening) for later use.

The physicochemical properties of the hematite colloids were characterized in this study. Briefly, mineral phase and functional groups of the hematite were identified usingX-ray diffraction (XRD; Bruker D8 Advance, Bruker Corp., Billerica, MA) and aNicolet 6700 Fourier transform infrared (FTIR) spectrometer (Thermo Scientific, Waltham, MA), respectively. The surface morphological features were observed with a scanning electron microscope (SEM; Zeiss 
Auriga 60, Carl Zeiss Microscopy GmbH, Jena, Germany). Crystal size and shape of the

hematite were examined via a transmission electron microscope (TEM; JEM-3100, JEOL, Japan), and the sample was prepared by placing 2-3 dropsof the hematite stock suspension (see below) on a 100 mesh carbon film-covered copper grid. The SSA was measured through a surface area and porosity analyzer (Micromeritics 3000, Micromeritics Instrument Corp., Norcross, GA) using the BET method. Isoelectric point (IEP) of the hematite suspended in $0.01 \mathrm{M} \mathrm{KNO}_{3}$ was determined using the Zetasizer Nano ZS (Malvern Instruments, Southborough, MA).

\subsection{Preparation of HANPs-hematite influent suspensions}

We first prepared a hematite stock suspension. Specifically, $0.050 \mathrm{~g}$ of hematite dry powder was added in $500 \mathrm{~mL}$ deionized (DI) water. The suspension was sonicated in a water bath at $25^{\circ} \mathrm{C}$ for $1 \mathrm{~h}$ to disperse particles and was then centrifuged at $350 \mathrm{~g}$ for $1 \mathrm{~min}$ to allow settlement of large aggregated particles (>2 $\mu \mathrm{m}$ diameter)based on the Stokes' law of settling. The supernatant of the suspension was carefully decanted and stored as the hematite stock suspension, and its concentration was measured using aDU Series $640 \mathrm{UV}$-vis spectrometer (Beckman Instruments Inc., Fullerton, CA) at the wavelength of $460 \mathrm{~nm}$ and was $\sim 70 \mathrm{mg} \mathrm{L}^{-1}$ (see supplementary material S1 and Fig. S1).

The HANPs-hematite influent suspension was prepared by weighting $0.030 \mathrm{~g}$ of HANPs dry powder to a precalculated volume of the hematite stock suspension, and then diluting the suspension with $\mathrm{KNO}_{3}$ solution (background electrolyte) to a final volume of $150 \mathrm{~mL}$. The concentrations of HANPs, hematite, and $\mathrm{KNO}_{3}$ in the influent were $200 \mathrm{mg} \mathrm{L}^{-1}, 50 \mathrm{mg} \mathrm{L}$, and $0.1 \mathrm{mM}$, respectively. A high concentration of $200 \mathrm{mg} \mathrm{L}^{-1}$ was chosen for HANPs to obtainsufficient amount of phosphate for isotopic measurements (described below). To reveal the 
162 role of $\mathrm{pH}$ on the cotransport of HANPs and hematite, the $\mathrm{pH}$ of HANPs-hematite influents 163 (background electrolyte of $0.1 \mathrm{mM} \mathrm{KNO}_{3}$ ) was adjusted to environmentally relevant values (6.5, 1647.5 , and 10.5) using $1 \mathrm{mM} \mathrm{HNO}_{3}$ or $\mathrm{NaOH}$. A pH of 10.5 was chosen to reverse the surface 165 charge of hematite due to its high IEP $(\mathrm{pH}=7.0-9.3)$ (Kosmulski, 2011). Similarly, additional 166 HANPs-hematite influents were prepared with $\mathrm{KNO}_{3}$ solution andSuwannee River humic acid 167 (SRHA) stock solution(see supplementary material S2) to study the coupled effect of 168 environmentally relevant concentrations of monovalent electrolyte $\left(0.1,10\right.$, and $\left.50 \mathrm{mM} \mathrm{KNO}_{3}\right)$ 169 (Sigg and Stumm, 2011) and NOM (1 mg L L SRHA) (Aiken, 2014) on the cotransport of 170 HANPs and hematite. Solution chemistries of the HANPs-hematite influents are summarized in 171 Table 1.

Electrophoretic mobility (EM) of the HANPs-hematite influentsand individual HANPs suspensionsat the desired solution chemistries was measured using the Zetasizer Nano ZS, as described earlier(Wang et al., 2012a; 2015a), and converted to zeta ( $\zeta)$ potentials using the Smoluchowski equation (Elimelech et al., 1995). The average hydrodynamic diameter $\left(D_{\mathrm{H}}\right)$ of the HANPs-hematite influents and individual HANPssuspensionsunder different experimental

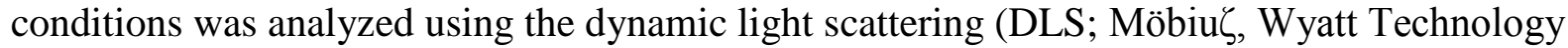
Corp., Santa Barbara, CA). Standard deviations were estimated based on >10 measurements conducted on three replicate samples for each experimental condition. The $\zeta$-potential and $D_{\mathrm{H}}$ valueof individual HANPs were thenused in combination with the Derjaguin-Landau-VerweyOverbeek (DLVO) theory (Derjaguin and Landau, 1941; Verwey and Overbeek, 1948) to computethe interaction energy between HANPs and sand grains over the range of solution chemistries investigated(see supplementary material S3).TEM was applied to visually examine 
the interactions such as homo-aggregation of HANPs and hematite, and hetero-aggregation between HANPs and hematite at selected solution chemistries.

\subsection{Column experiments}

column transport studies. The column was dry packed with $31.4 \mathrm{~g}$ of the cleanedsand (bulk 
density of $1.54 \mathrm{~g} \mathrm{~cm}^{-3}$ ) and then purged with $\mathrm{CO}_{2}$ in an upward flow direction for $30 \mathrm{~min}$ to ensure water saturation. Afterwards, DI water was injected in the upward flow direction at $q=$ $0.044 \mathrm{~cm} \min ^{-1}$ to slowly saturate the packed column. Column porosity was determined gravimetrically to be $\sim 0.30$.

After saturating the column, a nonreactive tracer experiment $\left(50 \mathrm{mM} \mathrm{KNO}_{3}\right)$ was

212 performed to obtain hydrodynamic parameters for the column by fitting the measured tracer breakthrough curve (BTC) to the one-dimensional advection-dispersion equation (ADE) using the STANMOD code (Simunek et al., 1999). The same injection velocity was chosen in tracer and HANPs-hematite cotransport experiments for a given column. After the tracer test, $>20$ pore volumes (PVs) of background electrolyte solution were injected in the column to equilibrate pore-water solution chemistry. Five PVs of the HANPs-hematite influent suspension under different experimental conditions (Table 1) were injected in the column, followed by elution with 5 PVs of particle-free background electrolyte solution. The electrolyte concentration and Darcy velocity remained constant during each experiment. During pulse injection, the HANPs-hematite influent was periodically sonicated to avoid particle settlement particularly at low $\mathrm{pH}$ and flow rate (Wang et al., 2015a). Column effluents (3.4 mL each) were sampled continuously using the Foxy Jr. fraction collector (Teledyne Isco, Lincoln, NE).

At the conclusion of each cotransport experiment, the column was carefully dissected into 10 layers of 1-cm segments. Retained HANPs and hematite (hereafter referred to as retentate) were released from the sand grains by placing them in DI water or $1 \mathrm{mM} \mathrm{NaOH}$ solution(depending on suspension $\mathrm{pH}$ ), shaking at $50 \mathrm{rpm}$ for $1 \mathrm{~h}$, and sonicating at a low frequency of $20 \mathrm{kHz}$ for $30 \mathrm{~min}$ in a water bath at $25^{\circ} \mathrm{C}$ (Wang et al., 2015a). The concentrations of phosphate in the effluents and retentates were obtained using the phosphomolybdate method 
(Murphy and Riley, 1962), which was then used to calculate the concentrations of HANPs in the effluents and retentates. The UV-vis spectrophotometer was employed to quantify hematite concentrations in the effluents and retentates at the wavelength of $460 \mathrm{~nm}$, as described above.

Mass balance of HANPs (or hematite) was calculated based on the mass of HANPs (or hematite) in the effluent, the mass in the retentate, and total mass injected in the column.

Toreveal the cotransport mechanisms of HANPs and hematite in saturated sand columns,additional experiments were conducted. Dissolution of HANPs at varying pHs was monitored over the time frame of the cotransport experiment in batch experiments, given that HANPs are likely to dissolve at acidic $\mathrm{pH}$ (Wang et al., 2015a). Moreover, the $D_{\mathrm{H}}$ of HANPshematite samples in the effluents and retentates was measured to assess the aggregation of both particles during cotransport. Additionally, SEM equipped with energy-dispersive X-ray (EDX) spectrometry was used to explore the retention mechanisms of HANPs-hematite on the sand grains at selected solution chemistries.

\subsection{Measurements of phosphate oxygen isotope ratios $\left(\delta^{18} O_{P}\right)$}

In selected column experiments run at varying ISs and flow rates, HANPs-hematite samples in the influents, effluents, and retentates were individually processed for O-isotopic measurements. All samples were purified using the dissolution and crystallization method (Jaisi and Blake, 2014; Kolodny et al., 1983). We first used $2 \mathrm{M} \mathrm{HNO}_{3}$ to completely dissolve the HANPs-hematite samples at $60^{\circ} \mathrm{C}$. It was followed by cation resin treatment (Bio-Rad AG50W$\mathrm{X} 8$, Hercules, CA) to remove cations, primarily the $\mathrm{Ca}^{2+}$ and $\mathrm{Fe}^{3+}$, in the dissolved solution. For the samples containing SRHA (i.e., at varying ISs), the dissolved solution was first treated by theSupelite ${ }^{\mathrm{TM}}$ DAX-8 resin (Sigma-Aldrich) to remove SRHA before removing the cations. Two 
separate phosphate standards ( 10 and $20 \mu$ moles $\mathrm{Na}_{2} \mathrm{HPO}_{4}$ ) were processed in parallel to test the validity of sample processing and reliability of isotope results. The purified phosphate solution was finally precipitated as silver phosphate $\left(\mathrm{Ag}_{3} \mathrm{PO}_{4}\right)$.

All phosphate oxygen isotope ratios $\left(\delta^{18} \mathrm{O}_{\mathrm{P}}\right)$ were measured at the stable isotope facility at the University of Delaware. The $\mathrm{Ag}_{3} \mathrm{PO}_{4}$ was measured by online high-temperature thermal decomposition method using a Thermo-Chemolysis Elemental Analyzer (TC/EA at $1460{ }^{\circ} \mathrm{C}$ ) coupled to a Delta V continuous flow isotope ratio monitoring mass spectrometer (IRMS;

Thermo, Bremen, Germany). The $\delta^{18} \mathrm{O}_{\mathrm{P}}$ value of each sample was calibrated against two $\mathrm{Ag}_{3} \mathrm{PO}_{4}$ standards, YR-1aR-02 (-5.49\%) and YR-3.2 (+33.63\%) (Vennemann et al., 2002). All $\delta^{18} \mathrm{O}_{\mathrm{P}}$ values in this communication are reported relative to the Vienna Standard Mean Ocean Water (VSMOW) standard in units of permil (\%o).

\subsection{Mathematical modeling}

A one-dimensional form of the ADE with one kinetic attachment site was used to

267 simulate the blocking (a decreasing rate of attachment with time) BTCs(Simunek et al., 2013):

$$
\begin{aligned}
& \frac{\partial\left(\theta_{\mathrm{w}} C\right)}{\partial t}=\frac{\partial}{\partial z}\left(\theta_{\mathrm{w}} D \frac{\partial C}{\partial z}\right)-\frac{\partial(q C)}{\partial z}-\theta_{\mathrm{w}} \psi k_{\mathrm{a}} C \\
& \frac{\partial\left(\rho_{\mathrm{b}} S\right)}{\partial t}=\theta_{\mathrm{w}} \psi k_{\mathrm{a}} C
\end{aligned}
$$

268 where $\theta_{\mathrm{w}}$ is the volumetric water content [-], $C$ is the HANPs (or hematite) concentration in the 269 aqueous phase $\left[\mathrm{M} \mathrm{L}^{-3}, \mathrm{M}\right.$ and $\mathrm{L}$ denote units of mass and length, respectively], $t$ is the time [T, T 270 denotes time unit], zis the distance from column inlet [L], $D$ is the hydrodynamic dispersion 271 coefficient $\left[\mathrm{L}^{2} \mathrm{~T}^{-1}\right], q$ is the Darcy velocity $\left[\mathrm{L} \mathrm{T}^{-1}\right], \psi$ is a dimensionless function to account for 272 both time- and depth-dependent blocking [-], $k_{\mathrm{a}}$ is the attachment rate coefficient of HANPs (or 
hematite) from the aqueous phase to solid phase, $\rho_{\mathrm{b}}$ is the bulk density of porous medium [M

$\left.\mathrm{L}^{-3}\right]$, and $S$ is the solid-phase concentration of retained HANPs (or hematite) $\left[\mathrm{M} \mathrm{M}^{-1}\right]$. The expression for the blocking term $(\psi)$ is given as follows:

$$
\psi=\left(1-\frac{S}{S_{\max }}\right)\left(\frac{d_{50}+z}{d_{50}}\right)^{-\beta}
$$

276 where $d_{50}$ is the median grain size of porous medium [L], $\beta$ is an empirical parameter controlling 277 the shape of spatial distribution of retained HANPs (or hematite) [-], and $S_{\max }$ is the maximum 278 solid-phase concentration of retained HANPs (or hematite) $\left[\mathrm{M} \mathrm{M}^{-1}\right]$. The first term on the right 279 hand side of Eq. [3] accounts for filling of retention sites in a manner similar to the Langmuirian 280 blocking effect (Adamczyk et al., 1994), whereas the second term describes depth-dependent 281 retention, e.g., a decreasing rate of attachment with depth.

282 While the above model formulation is flexible and can account for blocking BTCs and 283 retention profiles (RPs) that are exponential, uniform, and hyperexponential with depth, 284 consideration of only these factors cannot account for the ripening BTCs (an appreciable 285 increase in deposition with time). Reversible, depth-dependent deposition that includes a term for 286 ripening was therefore used to fit the ripening BTCs as follows:

$$
\frac{\partial\left(\rho_{\mathrm{b}} S\right)}{\partial t}=\theta_{\mathrm{w}} \psi k_{\mathrm{d}} C-\rho_{\mathrm{b}} k_{\mathrm{r}} S \rho_{\mathrm{b}}+S \theta_{\mathrm{w}} C k_{\mathrm{int}}
$$

287 where $k_{\mathrm{d}}$ is the particle deposition rate coefficient $\left[\mathrm{T}^{-1}\right], k_{\mathrm{r}}$ is the particle release rate coefficient $288\left[\mathrm{~T}^{-1}\right]$, and $k_{\text {int }}$ is the particle interaction (e.g., homo- and hetero-aggregation) rate coefficient $\left[\mathrm{L}^{3}\right.$ $289 \mathrm{~T}^{-1} \mathrm{~N}^{-1}$ ]. Ripening often occurs when attractive particle-particle interaction enhances particle 290 deposition on the collector surface. Enhanced particle-particle deposition due to ripening is 291 simulated using the third term on the right hand side of Eq. [4], which assumes that ripening is 292 second-order with respect to concentration, and thus proportional to the frequency of collisions 
between particles in the aqueous phase $\left(\theta_{\mathrm{w}} C\right)$ and particles immobilized on the collector surface $\left(\rho_{\mathrm{b}} S\right)$. Please note that reverse the sign of $k_{\text {int }}$ can be used to indicate liberation (release) of retained particles when the particle-particle interaction is repulsive.

The one-site kinetic attachment model and the ripening model described above were numerically solved using the HYDRUS-1D code (Simunek et al., 2013). A nonlinear least square optimization routine based upon the Levenberg-Marquardt algorithm (Marquardt, 1963) was incorporated in the HYDRUS-1D code to obtain HANPs and hematite transport parameters, i.e., $S_{\mathrm{max}}, k_{\mathrm{a}}$, and $\beta$ for the one-site kinetic attachment model, and $k_{\mathrm{d}}, k_{\mathrm{r}}$, and $k_{\text {int }}$ for the ripening model.

\subsection{Statistical analysis}

To determine the statistical differences among measured parameters in this study, oneway ANOVA analysis was performed using the Tukey's Honestly Significant Different (HSD) test. All analyses were performed in SPSS 16.0 software and the differences of mean values were considered to be significant at the level of $p<0.05$.

\section{Results and Discussion}

\subsection{Characterization of hematite colloids}

Crystallinity and purity of as-synthesized hematite were examined using powder XRD

311 measurement (Fig. 1a). The narrow sharp peaks imply a highly crystalline hematite (PDF 01312 076-9683). No other peaks were observed, suggesting the high purity of the hematite. Further 313 evidence for the formation of hematite can be obtained from its FTIR spectrum (Fig. 1b): two 314 strong peaks at 802 and $891 \mathrm{~cm}^{-1}$ are the characteristic vibrations of Fe-O bonds (Schwertmann 315 and Cornell, 2000). SEM and TEM images show that the hematite hasa spindle morphology with 
an average diameter of $\sim 350 \mathrm{~nm}$ (Fig. 1c, d). BET measurement indicates that the SSA of hematite is $41.2 \mathrm{~m}^{2} \mathrm{~g}^{-1}$, which is in close agreement with literature results (Schwertmann and Cornell, 2000). The IEP of hematite is measured at $\mathrm{pH}$ around 9.0, as shown in the supplementary material Fig. S2. This result is consistent with reported IEP values $(\mathrm{pH}=7.0-9.3)$ for hematite (Kosmulski, 2011).

\subsection{Electrokinetic properties of HANPs-hematite influents, quartz sands, and individual} HANPs suspensions

The $\zeta$-potentials of HANPs-hematite influents, quartz sands, and individual HANPs suspensionsat the desired solution chemistries are shown in Table 2. The results indicatethat the HANPs-hematite influent, quartz sand, and individual HANPswerenegatively charged over the range of solution chemistries studied with the exception of the HANPs-hematite influent at $\mathrm{pH}$ 6.5, which is likely because the positively charged hematite (supplementary material Fig. S2) dominates the overall surface charge of the HANPs-hematite complex. The magnitude of $\zeta$ potential for HANPs-hematite influent, quartz sand, and individual HANPs increasedwith increasing $\mathrm{pH}$, attributed primarily to the dissociation of proton groups on HANPs (Wang et al., 332 2012b; 2015a), hematite (IIIes and Tombacz, 2006), and quartz sand (Stumm and Morgan, 1996), 333 which is a common observation documented in the literature(Elimelech et al., 1995). In the 334 presence of $1 \mathrm{mg} \mathrm{L}^{-1} \mathrm{SRHA}$, their $\zeta$-potentials became significantly $(p<0.05$, Table 2$)$ less 335 negatively charged at higher ISs due togreater compression (charge screening) of electrostatic 336 double layer of particles (Derjaguin and Landau, 1941; Verwey and Overbeek, 1948). These 337 results are consistent with previous findings (Elimelech et al., 1995). Regardless of solution 338 chemistry, the magnitude of $\zeta$-potentialfor the HANPs-hematite influent was always smaller than 
that of individual HANPs, due to the presence of positively chargedhematite (or less negatively charged hematite relative to HANPs, supplementary material Fig. S2) in HANPs-hematite influent.

\subsection{Average hydrodynamic diameters of HANPs-hematite influents and individual HANPS suspensions}

The average hydrodynamic diameter $\left(D_{\mathrm{H}}\right)$ of NPs is often considered as anindicator of NPs mobility in porous media (Keller et al., 2010; Wang et al., 2014b; 2015a). The $D_{\mathrm{H}}$ values ofHANPs-hematite influents and individual HANPs at varying solution chemistries are summarized in Table3. Apparently, the $D_{\mathrm{H}}$ valueof HANPs-hematite influentincreased significantly $(p<0.05)$ with decreasing $\mathrm{pH}$, particularly when the $\mathrm{pH}(6.5$ and 7.5$)$ was below the IEP of hematite $\left(\mathrm{IEP}_{\text {hematite }}=9.0\right)$. This is mainly due to greater homo-aggregation of HANPs and hematite, and hetero-aggregation between negatively charged HANPs and positively charged hematite at lower $\mathrm{pH}$, as expected from their $\zeta$-potentials (Table 2). TEM images of the HANPshematite influent at $\mathrm{pH} 7.5$ are shown in Fig. 2, which indicates that both homo-aggregation and hetero-aggregation occurred in the HANPs-hematite influent. Especially, the TEM size of the HANPs-hematite complexes reached up to $\sim 1 \mu \mathrm{m}$ (Fig. 2A). Similar findings were recently reported for the hetero-aggregation between NPs (e.g., carbon nanotube and hematite NPs, and gold and carbon nanotube NPs) (Huynh et al., 2012; Nabiul Afrooz et al., 2013) and between NP and colloid (e.g., $\mathrm{TiO}_{2} \mathrm{NP}$ and $\mathrm{SiO}_{2}$ colloid, and graphene oxide $\mathrm{NP}$ and goethite colloid) (Praetorius et al., 2014; Zhao et al., 2015). However, the $D_{\mathrm{H}}$ value of HANPs-hematite influent increased with increasing IS even in the presence of $1 \mathrm{mg} \mathrm{L}^{-1}$ SRHA, suggesting that the SRHA can only stabilize the HANPs-hematite influent to a limited extent. Similar results were obtained 
362 for the homo-aggregation of SRHA-coated hematite colloid with elevating $\mathrm{NaCl}$ concentration (Mylon et al., 2004).Again, the $D_{\mathrm{H}}$ value of HANPs-hematite influent waslarger than that of individual HANPs at agiven solution chemistry, consistent with their $\zeta$-potential trends (Table 2).

Given that the DLVO theory is not applicable to quantify interaction energy between complex (i.e., HANPs-hematite complex) and sand grain, the individual HANP was employed to represent the HANPs-hematite complex for DLVO interaction energy calculation. This is primarily because two critical parameters that determine DLVO interaction energy, i.e., $\zeta$ potential and particle size were comparable over the range of solution chemistries investigated (Tables 2-3). We anticipate that the overalltrends of DLVO interaction energy for HANPs-sand systemand HANPs-hematite-sand systemare similar in response to variability in solution chemistry(see supplementary material S3 in detail).

\subsection{Cotransport of HANPs and hematite}

\subsubsection{Effect of $\mathrm{pH}$}

Fig. 3 presents observed and fitted BTCs and RPs of HANPs and hematite, respectively, at varying $\mathrm{pHs}\left(6.5,7.5\right.$, and 10.5) when IS $=0.1 \mathrm{mM} \mathrm{KNO}_{3}$ and $q=0.44 \mathrm{~cm} \mathrm{~min}^{-1}$. The BTCs are plotted as normalized effluent concentrations $\left(C_{\mathrm{i}} / C_{\mathrm{o}}\right) v s$. PVs, and the RPs are plotted as normalized solid-phase concentration $\left(S / C_{\mathrm{o}}\right) v s$. distance from the column inlet. The total mass balances for both HANPs (83.1-109\%) and hematite (97.8-111\%, Table 1) were good, 381 indicating that our experimental procedures and protocols are reliable. The model-fitted 382 parameters and Pearson's correlation coefficient $\left(R^{2}\right)$ between observed and fitted data are 383 summarized in Table 4, which reflects that either the one-site kinetic attachment model or the 
ripening model was able to sufficiently capture the main features of HANPs and hematite cotransport and retention $\left(R^{2}=0.858-1.00\right)$.

The $\mathrm{pH}$ was found to have a significant influence on the cotransport and retention of HANPs and hematite. The greatest mobility ofboth HANPs and hematite occurred at $\mathrm{pH}$ of 10.5 (Fig. 3 and Table 1)due, in part,to the highest electrostatic repulsion betweenHANPs (including hematite and HANPs-hematite complex)and sand grains (see supplementary material Fig. S3a).In particular, the values of maximum retention capacity $\left(S_{\max } / C_{\mathrm{o}}\right)$ for both HANPs and hematite obtained at $\mathrm{pH} 10.5$ using the one-site kinetic attachment model (Table 4) were low, meaning that the overall retention for both particles is limited. In addition, the homo-aggregation of HANPs and hematite in the influent was less pronounced at $\mathrm{pH} 10.5$ than at $\mathrm{pHs} 6.5$ and 7.5 (Table 3), further contributing to the high mobility of HANPs and hematite at pH 10.5.

At low pHs of 6.5 and 7.5, both homo-aggregation and hetero-aggregation of HANPs and hematite in the influents were significant (Table 3), thereby yielding the low mobility of both particles (Fig. 3 and Table 1). Specifically, the ripening BTCs were encountered for both particles with the exception of HANPs at pH 6.5 (Fig. 3a, c), signifying that particle (homo- and hetero-) aggregation occurs during cotransport. These observed ripening BTCs can also be quantified by the model-fitted parameters $k_{\text {int }}, k_{\mathrm{d}}$, and $k_{\mathrm{r}}$, which reflect the interaction between particles $\left(k_{\text {int }}\right)$, deposition of particles on the solid phase $\left(k_{\mathrm{d}}\right)$, and release of particles from the solid phase, respectively (Table 4 ). The values of $k_{\text {int }}$ and $k_{\mathrm{d}}$ were nearly 2 -orders of magnitude greater than those of $k_{\mathrm{r}}$, indicative of the predominance of particle interaction (homo- and heteroaggregation) and deposition in determining the mobility of HANPs and hematite. Based on the classical filtration theory (CFT) (Yao et al., 1971), deposition mechanisms of interception and sedimentation are expected to play pivotal roles in particle retention since the $D_{\mathrm{H}}$ values of 
HANPs-hematite influents at pHs 6.5 and 7.5 were up to $1 \mu \mathrm{m}$ (Table 3 ). The SEM-EDX analysis of the particles retained on the sand grains excavated from the column inlet $(0-1 \mathrm{~cm})$ after completion of the cotransport test at $\mathrm{pH} 7.5$ supports this hypothesis (Fig. 4).

Surprisingly, the transport of HANPs was approximately 7-fold greaterat $\mathrm{pH} 6.5$ than at pH $7.5\left(M_{\text {eff }}=38.9 v s .5 .67 \%\right.$, Fig. 3aandTable 1$)$, which isopposite tothe resultsfor thehematite at pHs6.5 and7.5 (Fig. 3cand Table 1).Since dissolution of HANPs at acidic pHplayed appreciable roles in the cotransport of HANPs and goethite NPs in porous media (Wang et al., 2015a), the dissolution ofHANPs in HANPs-hematite influents $v s$. pHwas examined in batch experiments(see supplementary material Fig. S4).No detectable dissolution of HANPs was encountered when $\mathrm{pH} \geq 7.5$, consistent with ourrecentfindings (Wang et al., 2015a). In contrast, 4.4\% HANPs was dissolved at $\mathrm{pH} 6.5$, forming dissolved $\mathrm{PO}_{4}{ }^{3-}$ ions. Therefore, the high breakthrough of HANPs obtained at $\mathrm{pH} 6.5$ was due, in part, to the high mobility of dissolved $\mathrm{PO}_{4}{ }^{3-}$ ions. Nevertheless, thelimited dissolution (4.4\%) of HANPs at $\mathrm{pH} 6.5$ in batch system cannot completely account for the high mobility $\left(M_{\mathrm{eff}}=38.9 \%\right)$ of HANPsin column system. We anticipate that dissolution of HANPs is much greater in "dynamic" column system than inbatch systemsince dissolved $\mathrm{PO}_{4}{ }^{3-}$ ion was progressively eluted out from the column. This is especially true when injecting pH 6.5 background electrolytes to dissolve retained HANPs (Wang et al., 2015a). In addition, homo-aggregation of HANPs is also likely to be weakened due to a decrease in overall collision efficiency since the HANPs were gradually dissolved in column system. Hence,enhanced dissolution of HANPs in "dynamic" column system andreduced homoaggregation among HANPs populationsareinvolved inthe high mobility of HANPs at pH 6.5. The RPs for both HANPs and hematite typically displayed a hyperexponential shape with greater retention in the column inlet $(0-4 \mathrm{~cm})$ and rapidly decreasing retention with depth (Fig. 
3b, d), which is in contrast with CFT that predicts an exponential shape with depth (Yao et al., 1971). The hyperexponential RPs were less pronounced at higher $\mathrm{pH}$. The $D_{\mathrm{H}}$ values of HANPshematite samples in the effluents and retentates are shown in Table 3. Irrespective of $\mathrm{pH}$, the $D_{\mathrm{H}}$ value among the retentate reservoir decreased unidirectionally with increasing transport distance, i.e., from 0-4 cm. These observationsare indicative of "sizeselective retention" in porous media (Yao et al., 1971) with larger particles preferentially retained near the column inlet due to greater interception and sedimentation (Fig. 4) and smaller ones transported farther. The $D_{\mathrm{H}}$ values of effluent particles were substantially smaller than those of the retentates, further supporting that the sizeselective retention occurred. The sizeselective retention has been increasingly demonstrated to yield the hyperexponential RPs in NP transport studies (Jiang et al., 2012; Wang et al., 2012a; 2015a). Additionally, physical straining is also likely involved in the ripening BTCs and hyperexponential RPs for both HANPs and hematite at pHs 6.5 and 7.5 (Fig. 3), since 442 the maximum values of $D_{\mathrm{H}} / d_{50}$ (i.e., $2.7 \times 10^{-3}$ and $2.6 \times 10^{-3}$, respectively, at pHs 6.5 and 7.5) 443 were larger than the threshold required for straining $\left(2.0 \times 10^{-3}\right)$ (Bradford et al., 2002).

In comparing the cotransport of HANPs and hematite with their individual transport at selected $\mathrm{pH}$ (see supplementary material Fig. S5), it is evident that greater mobility of HANPs (or hematite) occurred during cotransport at $\mathrm{pH} 10.5$ (Fig. S5a, b). Since the maximum retention capacity of collector $\left(S_{\max } / C_{\mathrm{o}}\right)$ for both particles is limited at $\mathrm{pH} 10.5$ (described above), competition for these favorable retention sites by negatively charged HANPs and hematite contributes to the higher mobility of both particles during their cotransport than individual transport. Similar findings were reported for the cotransport of bactericide and colloid (bismerthiazol and montmorillonite colloid) (Shen et al., 2015) and NPs $\left(\mathrm{C}_{60}\right.$ and $\left.\mathrm{TiO}_{2} \mathrm{NPs}\right)(\mathrm{Cai}$ et al., 2013) in saturated sand columns. Conversely, the addition of hematite in HANPs influent 
inhibited the transport of HANPs at $\mathrm{pH} 7.5$ and vice versa (Fig. S5c, d). This could be due to greater hetero-aggregation between HANPs and hematite in the influents at $\mathrm{pH} 7.5$ compared to pH 10.5.

\subsubsection{Effect of IS}

Fig. 5 presents observed and fitted BTCs and RPs of HANPs and hematite, respectively, under different ISs $\left(0.1,10\right.$, and $\left.50 \mathrm{mM} \mathrm{KNO}_{3}\right)$ at $\mathrm{pH} \sim 7.5$ and $q=0.44 \mathrm{~cm} \mathrm{~min}^{-1}$ in the presence of $1 \mathrm{mg} \mathrm{L}^{-1} \mathrm{SRHA}$. The transport of both particles decreased and retention increased with increasing IS, which are common observations in the transport of single-species colloid/NP in porous media (Chowdhury et al., 2011; Grolimund et al., 1998; Kretzschmar et al., 1997; Wang et al., 2014a; 2015b). These findings can be partly explained by enhanced particle aggregation (Table 3) and reduced electrosteric repulsion between particle-sand systems at higher ISs (supplementary material Fig. S3b). Moreover, nanoscale heterogeneity on collector surfaces is increasingly interpreted to play vital roles in colloids particularly NPs retention (Duffadar and Davis, 2008), which increases with increasing IS. Consequently, nanoscale heterogeneity is expected to cause more particleretention at higher ISs.

The shapes of BTCs and RPs for both particles displayed a transition from blocking to 470 ripening (Fig. 5a, c) and from hyperexponential to flat (Fig. 5b, d), respectively, in response to 471 increases in IS. The ripening BTCs observed for both HANPs and hematite indicate that $1 \mathrm{mg}$ $472 \mathrm{~L}^{-1}$ SRHA cannot effectively stabilize the HANPs-hematite complexes at $\mathrm{pH} \sim 7.5$ when IS $\geq 10$ mM. Specifically, the $D_{\mathrm{H}}$ values of HANPs-hematite influents were 624 and $747 \mathrm{~nm}$ under $474 \mathrm{KNO}_{3}$ concentrations of 10 and $50 \mathrm{mM}$, respectively, which were $\sim 3$ and 4 -fold greater than that at $0.1 \mathrm{mM} \mathrm{KNO}_{3}(181 \mathrm{~nm})$ (Table 3$)$. Close examination of the $D_{\mathrm{H}}$ values for HANPs-hematite 
samples among the influent, effluent, and retentate reservoirs again reveals occurrence of sizeselective retention over the range of ISs considered (Table 3). Furthermore, this sizeselective retention became more pronounced at higher ISs, thereby yielding the more noticeable hyperexponential RPs at higher ISs (Jiang et al., 2012).

Previous studies indicated that the attractive secondary minimum region is likely involved in colloids/NPs retention particularly at higher ISs (Hahn and O'Melia, 2004; Tufenkji and Elimelech, 2005). Eluting the columns with DI water (IS $\approx 0$ ) after completion of the cotransport experiments released $\sim 8.87$ and $13.8 \%$ of the total injected HANPs, and $\sim 2.65$ and $4.92 \%$ of the total injected hematite under ISs of 10 and $50 \mathrm{mM} \mathrm{KNO}_{3}$, respectively (see supplementary material Fig. S6). These observations highlight that the secondary minimum is responsible for particle retention when IS was $\geq 10 \mathrm{mM}$. The mobility of HANPs was always less than that of hematite in the presence of $1 \mathrm{mg} \mathrm{L}^{-1}$ SRHA (Fig. 5 and Table 1). This is largely due to less sorption of negatively charged NOM onto negatively charged HANPs than to positively charged hematite (Tipping and Higgins, 1982), thereby resulting in less electrosteric repulsion to the HANPs relative to the hematite (Chen et al., 2012). Additionally, greater retention in the secondary minimum may also contribute to HANPs' lower mobility of compared to hematite. The BTCs for cotransport and individual transport of HANPs and hematite when SRHA $493=1 \mathrm{mg} \mathrm{L}^{-1}$ under ISs of 10 and $50 \mathrm{mM}$ are shown in the supplementary material Fig. S7. The 494 individual transport of HANPs and hematite was much greater than their cotransportparticularly 495 at a higher IS (50 $\left.\mathrm{mM} \mathrm{KNO}_{3}\right)$, consistent with the results obtained at $\mathrm{pH} 7.5$ (Fig. S5c, d). Nonetheless, ripeningstill occurred for the individual transport of HANPs when SRHA = $1 \mathrm{mg}$ $\mathrm{L}^{-1}$ and IS $\geq 10 \mathrm{mM}$ (Fig. S7a, c), indicating that $1 \mathrm{mg} \mathrm{L}^{-1}$ SRHA cannot stabilize the HANPs at high ISs $(\geq 10 \mathrm{mM})$. Conversely, blocking were observed for the individual transport of hematite 
when SRHA $=1 \mathrm{mg} \mathrm{L}^{-1}$ at ISs of 10 and $50 \mathrm{mM}$,mirroring the pivotal roleof HANPs in weakening the transport of hematite even in the presence of SRHA.

The ripening model provided a good description for the BTCs and RPs of both particles under ISs of 10 and $50 \mathrm{mM} \mathrm{KNO}_{3}$ (Fig. 5 and Table 4). The values of $k_{\text {int }}$ and $k_{\mathrm{d}}$ for HANPs and hematite were much greater than those of $k_{\mathrm{r}}$, suggesting that interaction and deposition of particles determine their mobility, as observed at low $\mathrm{pH}$ tests (6.5 and 7.5). The value of $k_{\mathrm{d}}$ was greater and the value of $k_{\mathrm{r}}$ was lower at a higher IS, meaning that particle deposition depends on the attractive interaction (e.g., nanoscale heterogeneity of collector and secondary minimum), which increases with increasing IS.

\subsubsection{Effect of flow rate}

To determine the role of hydrodynamics on the cotransport and retention of HANPs and hematite, experiments were conducted under different Darcy velocities $(q=0.44,0.22$, and 0.044 $\mathrm{cm} \mathrm{min}^{-1}$ ) at $\mathrm{pH} 7.5$ and $\mathrm{IS}=0.1 \mathrm{mM} \mathrm{KNO}_{3}$ (Fig. 6). Higher mass effluent recovery and less retention were encountered for both particles at higher $q$, which is in agreement with published results (Chowdhury et al., 2011; Grolimund et al., 1998; Harter et al., 2000; Kretzschmar et al., 1997; Li et al., 2008; Wang et al., 2012b;2014a). The ripening BTCs and hyperexponential RPs 516 observed at varying $q$ indicate that homo-aggregation and hetero-aggregation of HANPs and 517 hematite determine their mobility (described above). Consistent with the trends obtained at 518 different pHs and ISs, the individual transport of HANPs and hematite was always greater than 519 their cotransport, as shown in the supplementary material Fig. S8. These observations again 520 support the fact that hetero-aggregation between negatively charged HANPs and positively charged hematite at $\mathrm{pH} \sim 7.5$ weakens the mobility of both particles. Comparison of the $D_{\mathrm{H}}$ 
values of HANPs-hematite samples in the influents, effluents, and retentates reveals that particle aggregation and sizeselective retention were more pronounced at lower $q$ (Table 3), which accounts for the more significant ripening and hyperexponential RPs at lower $q$. The ripening BTCs occurred for both the co- and individual-transport of HANPs and hematite, indicating that the mobility of both particles is very limited in the absence of NOM, even when IS was as low as $0.1 \mathrm{mM} \mathrm{KNO}_{3}(\mathrm{pH} \sim 7.5)$.

The ripening model again well approximated the BTCs and RPs of both HANPs and hematite at different $q$ (Fig. 6 and Table 4). Consistent with the results attained at low pH tests (6.5 and 7.5), the values of $k_{\mathrm{r}}$ were 2-3 orders of magnitudesmaller than those of $k_{\text {int }}$ and $k_{\mathrm{d}}$, indicative of the insignificant role of particle release (i.e., irreversible retention). The CFT (Yao et al., 1971) predicts that the value of $k_{\mathrm{d}}$ is proportional to $q$ raised to the $1 / 3$ power (Schijven and Hassanizadeh, 2000). Nonetheless, the overall rate of advection is proportional to $q$ such that a systematic decrease in particle retention is anticipated with an increase in $q$. The observed $k_{\mathrm{d}}$ trends for both HANPs and hematite are therefore consistent with the CFT prediction (Table 4). Similarly, the absolute values of $k_{\text {int }}$ also increased with increasing $q$, consistent with the trend for the $k_{\mathrm{d}}$. This finding reflects that HANPs-hematite interaction is dependent on $q$ and increases with increasing $q$.

\subsection{Phosphate oxygen isotope ratios of HANPs and isotopic fractionation}

\section{3.5.1. IS effect}

542 To assess the role of environmentally relevant IS on phosphate oxygen isotope

543 fractionation among HANPs populations during cotransport, selected HANPs-hematite samples in the influents, effluents, and retentates recovered at ISs of 10 and $50 \mathrm{mM} \mathrm{KNO}_{3}$ in the presence 
of $1 \mathrm{mg} \mathrm{L}^{-1}$ SRHA were individually processed to quantify their O-isotopic composition. The IS was found to exerta marked impact on the isotope fractionation of HANPs (Fig. 7). Regardless of IS, the $\delta^{18} \mathrm{O}_{\mathrm{P}}$ values of HANPs among the influent, effluent, and retentate reservoirsfollowed the order: effluent $>$ influent $>$ retentate. For the effluent reservoir, the $\delta^{18} \mathrm{O}_{\mathrm{P}}$ valuesdecreased with eluted PV and tended to approach the influent $\delta^{18} \mathrm{O}_{\mathrm{P}}$ values (10.70\%). Similarly, this isotopic fractionation between retentates and influents became less significant at greater depths (e.g., from 1-5 cm). This fractionation was more prominent at a higher IS (i.e., $50 \mathrm{mM} \mathrm{KNO}_{3}$ ). For instance, at IS $=10 \mathrm{mM} \mathrm{KNO}_{3}$, the O-isotopic fractionation between effluents and influents at the early stage of transport (i.e., 2 PV) was $\sim 0.82 \%$, whereas the difference was $\sim 1.32 \%$ o when IS $=50 \mathrm{mM} \mathrm{KNO}_{3}$ (Fig. 7). A similar trend was obtained between influents and retentates at the tested ISs. These findings are in close agreement with a recent study (Jaisi, 2013) in which isotope fractionation of dissolved $\mathrm{PO}_{4}{ }^{3-}$ ion was examined at differentISs and flow rates. Specifically, at $q=0.0049 \mathrm{~cm} \mathrm{~min}^{-1}$ over a wide range of ISs $(1-100 \mathrm{mM} \mathrm{KCl})$, the isotope fractionation between the effluent and influent phosphates at the initial stage (i.e., 2 PV) was $\sim 1.10 \%$ with isotopically-heavier phosphates $\left(\mathrm{P}^{18} \mathrm{O}_{4}\right)$ preferentially passed through the column packed with natural sediments because the lighter phosphates $\left(\mathrm{P}^{16} \mathrm{O}_{4}\right)$ were thermodynamically favorably retained (sorbed) by the sediments (Jaisi, 2013; Jaisi et al., 2010). It was further pointed that this isotopic fractionation decreased gradually and became insignificantas more phosphates passed through the column due to efficient ion exchange between aqueous and retained (sorbed) phosphates (Jaisi, 2013; Jaisi et al., 2010). The ion exchange effect has long been proposed to interpret the isotopic fractionation between dissolved ion and solid mineral, such as $\mathrm{Fe}$ isotope fractionation between aqueous $\mathrm{Fe}^{2+/ 3+}$ ion and iron oxide minerals (e.g., ferrihydrite, goethite, hematite, and magnetite) (Beard et al., 1999; Cwiertny et al., 2008; Gorski 
et al., 2012; Skulan et al., 2002). However, in this study, the ion exchange is unlikely to account for the isotope fractionation of HANPs obtained at ISs of 10 and $50 \mathrm{mM} \mathrm{KNO}_{3}(\mathrm{pH} \sim 7.5)$ since no dissolution of HANPs occurred (see supplementary material Fig. S4).

Given that the particles including NPs are expected to behave differently than the dissolved ions, there should be other different mechanism/s governing the isotope fractionation of HANPs during transport. Since particle aggregation is apparent particularly at higher ISs (Table 3), it is intuitive to assume that particle aggregation could be a plausible mechanism responsible for the isotopic fractionation at varying ISs (Fig. 7). This is because the aggregation is a diffusion-controlled reaction, which is analogous to the reactions of nucleation and Ostwald ripening during crystal growth processes that commonly yield non-equilibrium and kinetic isotopic fractionation (Guilbaud et al., 2010; Steefel and Van Cappellen, 1990; Stoffregen, 1996; Watson and Muller, 2009). The origin of the primary driving force for nucleation and Ostwald ripening lies in the interfacial free energy of a mineral, which involves a redistribution (e.g., dissolution and then reprecipitation) of mass from small particles to large particles in the system (Steefel and Van Cappellen, 1990; Stoffregen, 1996). That is, an increase in average particle size and a decrease in the number of particles with time thermodynamically occur due to a net transfer of material from small to large particles (the overall reactive surface area diminishes correspondingly) (Steefel and Van Cappellen, 1990; Stoffregen, 1996; Waychunas et al., 2005). In particular, Guilbaud et al. (2010) found that the Fe isotope fractionation between aqueous $\mathrm{Fe}^{2+}$ ion and nanoparticulate mackinawite (FeS) was up to $1.17 \%$ at $25^{\circ} \mathrm{C}$, which is interpreted by particle aggregation. All these interpretations reflect that the isotope fractionation of HANPs during transport is most likely initiated by particle aggregation. Theoretically, the heteroaggregation between isotopically-lighter HANP (i.e., $\mathrm{P}^{16} \mathrm{O}_{4}$ ) andhematite is more 
thermodynamically favored than the heavier HANP analogue (e.g., $\mathrm{P}^{18} \mathrm{O}_{4}$ ) due to lower enthalpy and interfacial free energy of the lighter one compared to the heavier one (Navrotsky et al., 2008; Steefel and Van Cappellen, 1990; Waychunas et al., 2005). Since the sizeselective retention occurs during HANPs transport at various ISs (Table 3), the HANPs with isotopically-light phosphates (i.e., $\mathrm{P}^{16} \mathrm{O}_{4}$ ) are expected to preferentially hetero-aggregate with hematite anddeposit gradually along the column profile, whereas those with heavy phosphates (i.e., $\mathrm{P}^{18} \mathrm{O}_{4}$ ) heteroaggregate slowly and ultimately elute from the column, which results in the retentates and effluents enriching in $\mathrm{P}^{16} \mathrm{O}_{4}$ and $\mathrm{P}^{18} \mathrm{O}_{4}$, respectively. In addition, particle aggregation in the retentate reservoir was less pronounced at greater depths (Table 3), which likely accounts for the smaller isotopic fractionation between retentates and influents at greater depths (Fig. 7).

Similarly, the isotopic fractionation was less significant at lower ISs, likely attributable to the less sizeselective retention of HANPs during transport (Table 3).

\section{3.5.2. Flow rate effect}

The flow rate was recently found to exert a marked influence on the isotope fractionation of dissolved $\mathrm{PO}_{4}{ }^{3-}$ ion in saturated sediment columns (Jaisi, 2013). Our data also demonstrate 607 that the isotope fractionation of HANPs was also dependent on the flow rate (Fig. 8). Again, the $608 \delta^{18} \mathrm{O}_{\mathrm{P}}$ values of HANPs were in the following order of effluent $>$ influent $>$ retentate, irrespective 609 of flow rate. At $q=0.44 \mathrm{~cm} \mathrm{~min}^{-1}$, the O-isotopic composition in the retentate reservoir became 610 gradually heavier at greater depths (e.g., from 1-4 cm), consistent with the results obtained at 611 different ISs. This is likely due to less aggregation of HANPs at greater depths, as described 612 above (Table 3). The isotopic fractionation decreased progressively and became insignificant 613 with decreasing $q$. For example, at the depth of $1 \mathrm{~cm}$, the $\delta^{18} \mathrm{O}_{\mathrm{P}}$ values of retentate increased 


\section{Conclusions}

Column experiments were designed to elucidate the cotransport and retention of HANPs and hematite at various $\mathrm{pHs}$, ISs, and flow rates. Our results demonstrated that the cotransport and retention of HANPs and hematite are highly sensitive to the physicochemical factors considered. The mobility of HANPs and hematite during cotransport increased with increasing $\mathrm{pH}$ and flow rate, and decreasing IS. Nevertheless, the mobility of both HANPs and hematite was substantially lower during cotransport than their individual transport, primarily due to greater aggregation of HANPs, hematite, and HANPs-hematite complexes when both particles were copresent in the suspension. During cotransport, the shape of BTCs and RPs for both particles frequently transformed from blocking to ripening with time and from flat to hyperexponential with depth, respectively, in response to variability in the tested physicochemical factors. A one-site kinetic attachment model can adequately capture the main features of the blocking BTCs and RPs that are hyperexponential or flat, whereas a ripening model that includes attractive particle-particle interaction has to be employed to simulate the ripening BTCs. Model-fitted parameters exhibited systematic trends with tested experimental conditions.

For the first time, the phosphate oxygen isotope fractionation among HANPs populations during cotransport was explored under various ISs and flow rates. A small isotopic fractionation occurred $(\leq 2 \%)$ between effluent and influent and between retentate and influent, mostly likely initiated by hetero-aggregation between HANPs and hematite. Furthermore, this isotopic fractionation became more pronounced at higher ISs due to enhanced aggregation. Larger isotopic fractionation was obtained at a higher flow rate, but this fractionation was decreased with decreasing flow rate due to less mass transfer between influent and effluent HANPs. To 
date, accurate detection and characterization of NPs in complex subsurface environments are still rather challenging. Given that different sources of phosphate-based NPs may hold distinct $\delta^{18} \mathrm{O}_{\mathrm{P}}$ signatures, and the transport-related isotope fractionation is insignificant, isotope tracing could serve as a promising tool to identify the sources andtransport of phosphate-based NPs in complex subsurface environments.

\section{Supplementary material}

\section{Acknowledgments}

\section{References}

Adamczyk, Z., Siwek, B., Zembala, M., Belouschek, P., 1994. Kinetics of localized adsorption of colloid particles. Adv. Colloid Interface Sci. 48, 151-280. 
Aiken, G.R., 2014. Dissolved organic matter in aquatic systems. In: Ahuja, S. (Ed.), Comprehensive Water Quality and Purification. Elsevier, Waltham, pp: 205-220.

Balasundaram, G., Sato, M., Webster, T.J., 2006. Using hydroxyapatite nanoparticles and decreased crystallinity to promote osteoblast adhesion similar to functionalizing with RGD. Biomaterials 27(14), 2798-2805.

Beard, B.L., Johnson, C.M., Cox, L., Sun, H., Nealson, K.H., Aguilar, C., 1999. Iron isotope biosignatures. Science 285(4535), 1889-1892.

Blake, R.E., O’Neil, J.R., Garcia, G.A., 1997. Oxygen isotope systematics of biologically mediated reactions of phosphate: I. Microbial degradation of organophosphorus compounds. Geochim. Cosmochim. Acta 61(20), 4411-4422.

Bradford, S.A., Yates, S.R., Bettahar, M., Simunek, J., 2002. Physical factors affecting the transport and fate of colloids in saturated porous media. Water Resour. Res. 38(12), DOI:10.1029/2002WR001340.

Cai, L., Tong, M.P., Ma, H., Kim, H., 2013. Cotransport of titanium dioxide and fullerene nanoparticles in saturated porous media. Environ. Sci. Technol. 47(11), 5703-5710.

Chen, G., Liu, X., Su, C., 2012. Distinct effects of humic acid on transport and retention of $\mathrm{TiO}_{2}$ rutile nanoparticles in saturated sand columns. Environ. Sci. Technol. 46(13), 7142-7150.

Chen, J.H., Wang, Y.J., Zhou, D.M., Cui, Y.X., Wang, S.Q., Chen, Y.C., 2010. Adsorption and desorption of $\mathrm{Cu}(\mathrm{II}), \mathrm{Zn}(\mathrm{II}), \mathrm{Pb}(\mathrm{II})$, and $\mathrm{Cd}(\mathrm{II})$ on the soils amended with nanoscale hydroxyapatite. Environ. Prog. Sustain. Energy 29(2), 233-241.

Chen, L., Mccrate, J.M., Lee, J.C.M., Li, H., 2011. The role of surface charge on the uptake and biocompatibility of hydroxyapatite nanoparticles with osteoblast cells. Nanotechnology 22(10). DOI:10.1088/0957-4484/22/10/105708. 
Cheng, T., Saiers, J.E., 2015. Effects of dissolved organic matter on the co-transport of mineral colloids and sorptive contaminants. J. Contam. Hydrol. 177-178, 148-157.

Chowdhury, I., Hong, Y., Honda, R.J., Walker, S.L., 2011. Mechanisms of $\mathrm{TiO}_{2}$ nanoparticle transport in porous media: Role of solution chemistry, nanoparticle concentration, and flowrate. J. Colloid Interface Sci. 360(2), 548-555.

Cwiertny, D.W., Handler, R.M., Schaefer, M.V., Grassian, V.H., Scherer, M.M., 2008.

Interpreting nanoscale size-effects in aggregated Fe-oxide suspensions: Reaction of Fe(II) with Goethite. Geochim. Cosmochim. Acta 72(5), 1365-1380.

Derjaguin, B.V., Landau, L.D., 1941. Theory of the stability of strongly charged lyophobic sols and of the adhesion of strongly charged particles in solutions of electrolytes. Acta Physicochim. USSR 14, 633-662.

Duba, A.G., Jackson, K.J., Jovanovich, M.C., Knapp, R.B., Taylor, R.T., 1996. TCE remediation using in situ, resting-state bioaugmentation. Environ. Sci. Technol. 30(6), 1982-1989.

Duffadar, R.D., Davis, J.M., 2008. Dynamic adhesion behavior of micrometer-scale particles flowing over patchy surfaces with nanoscale electrostatic heterogeneity. J. Colloid Interface Sci. 326(1), 18-27.

Elimelech, M., Gregory, J., Jia, X., Williams, R., 1995. Particle Deposition and Aggregation: Measurement, Modelling and Simulation. Butterworth-Heinemann: Woburn, MA.

Frossard, E., Brossard, M., Hedley, M.J., Meterell, A., 1995. Reactions controlling the cycling of P in soils. In: Tiessen, H., (ed.). Phosphorus in the Global Environment, chapter 7, pp: 107-137. New York: Wiley. SCOPE 54. 
Gorski, C.A., Handler, R.M., Beard, B.L., Pasakarnis, T., Johnson, C.M., Scherer, M.M., 2012. Fe atom exchange between aqueous $\mathrm{Fe}^{2+}$ and magnetite. Environ. Sci. Technol. 46(22), 12399-12407.

Grolimund, D., Elimelech, M., Borkovec, M., Barmettler, K., Kretzschmar, R., Sticher, H., 1998. Transport of in situ mobilized colloidal particles in packed soil columns. Environ. Sci. Technol. 32(22), 3562-3569.

Guilbaud, R., Butler, I.B., Ellam, R.M., Rickard, D., 2010. Fe isotope exchange between Fe(II) $)_{a q}$ and nanoparticulate mackinawite $\left(\mathrm{FeS}_{\mathrm{m}}\right)$ during nanoparticle growth. Earth Planet. Sci. Lett. 300(1-2), 174-183.

Hahn, M.W., O’Melia, C.R., 2004. Deposition and reentrainment of Brownian particles in porous media under unfavorable chemical conditions: some concepts and applications. Environ. Sci. Technol. 38(1), 210-220.

Handley-Sidhu, S., Renshaw, J.C., Moriyama, S., Stolpe, B., Mennan, C., Bagheriasl, S., Yong, P., Stamboulis, A., Paterson-Beedle, M., Sasaki, K., Pattrick, R.A.D., Lead, J.R., Macaskie, L.E., 2012. Uptake of $\mathrm{Sr}^{2+}$ and $\mathrm{Co}^{2+}$ into biogenic hydroxyapatite: Implications for biomineral ion exchange synthesis. Environ. Sci. Technol. 45(16), 6985-6990.

Harter, T., Wagner, S., Atwill, E.R., 2000. Colloid transport and filtration of Cryptosporidium parvum in sandy soils and aquifer sediments. Environ. Sci. Technol. 34(1), 62-70.

Huynh, K.A., McCaffery, J.F., Chen, K.L., 2012. Hetero-aggregation of multiwalled Carbon nanotubes and hematite nanoparticles: Rates and mechanisms. Environ. Sci. Technol. 46(11), 5912-5920. 
IIIes, E., Tombacz, E., 2006. The effect of humic acid adsorption on pH-dependent surface

Jaisi, D.P., 2013. Stable isotope fractionations during reactive transport of phosphate in packedbed sediment columns. J. Contam. Hydrol. 154, 10-19.

Jaisi, D.P., Blake, R.E., 2014. Advances in using oxygen isotope ratios of phosphate to understand phosphorus cycling in the environment. Adv. Agron. 125, 1-53.

Jaisi, D.P., Blake, R.E., Kukkadapu, R.K., 2010. Fractionation of oxygen isotopes in phosphate during its interactions with iron oxides. Geochim. Cosmochim. Acta 74(4), 3199-3212.

Jiang, X.J., Tong, M.P., Lu, R.Q., Kim, H., 2012. Transport and deposition of ZnO nanoparticles in saturated porous media. Colloids Surf., A 401, 29-37.

Joshi, S.R., Kukkadapu, R.K., Burdige, D.J., Bowden, M.E., Sparks, D.L., Jaisi, D.P., 2015. Organic matter remineralization predominates phosphorus cycling in the mid-Bay sediments in the Chesapeake Bay. Environ. Sci. Technol. 49(10), 5887-5896.

Keller, A.A., Wang, H., Zhou, D., Lenihan, H.S., Cherr, G., Cardinale, B.J., Miller, R., Ji, Z., 2010. Stability and aggregation of metal oxide nanoparticles in natural aqueous matrices. Environ. Sci. Technol. 44(6), 1962-1967.

Kolodny, Y., Luz, B., Navon, O., 1983. Oxygen isotope variations in phosphate of biogenic apatites, I. Fish bone apatite-rechecking the rules of the game. Earth Planet. Sci. Lett. 64(3), 398-404.

Kosmulski, M., 2011. The pH-dependent surface charging and points of zero charge: V. Update. J. Colloid Interface Sci. 353(1), 1-15. 
Kretzschmar, R., Barmettler, K., Grolimund, D., Yan, Y.D., Borkovec, M., Sticher, H., 1997. Experimental determination of colloid deposition rates and collision efficiencies in natural porous media. Water Resour. Res. 33(5), 1129-1137.

Lecuyer, C., Grandjean, P., Sheppard, S.M.F., 1999. Oxygen isotope exchange between dissolved phosphate and water at temperatures $\leq 135^{\circ} \mathrm{C}$ : Inorganic versus biological fractionations. Geochim. Cosmochim. Acta 63(6), 855-862.

Li, H., Jaisi, D.P. 2015. Oxygen atom exchange during phosphate sorption and desorption onto $\mathrm{Fe}-$ and Mn-oxides: An application of ${ }^{18} \mathrm{O}$ isotope labeling technique. Soil Sci. Soc. Am. J. DOI:10.2136/sssaj2015.04.0158.

Li, Y.S., Wang, Y.G., Pennell, K.D., Abriola, L.M., 2008. Investigation of the transport and deposition of fullerene $\left(\mathrm{C}_{60}\right)$ nanoparticles in quartz sands under varying flow conditions. Environ. Sci. Technol. 42(19), 7174-7180.

Liang, Y., Blake, R.E., 2006. Oxygen isotope signature of $\mathrm{P}_{\mathrm{i}}$ regeneration from organic compounds by phosphomonoesterases and photooxidation. Geochim. Cosmochim. Acta 70(15), 3957-3969.

Liang, Y., Blake, R.E., 2009. Compound- and enzyme-specific phosphodiester hydrolysis mechanisms revealed by $\delta^{18} \mathrm{O}$ of dissolved inorganic phosphate: Implications for marine P cycling. Geochim. Cosmochim. Acta 73(13), 3782-3794.

Liu, R., Lal, R., 2014. Synthetic apatite nanoparticles as a phosphorus fertilizer for soybean (Glycine max). Sci. Rep. 4, 5685-5691.

Marquardt, D.W., 1963. An algorithm for least-squares estimation of nonlinear parameters. J. Soc. Ind. Appl. Math. 11(2), 431-441. 
McCarthy, J.F., Zachara, J.M., 1989. Subsurface transport of contaminants. Environ. Sci. Technol. 23(5), 496-502.

Montalvo, D., McLaughlin, M.J., Degryse, F., 2015. Efficacy of hydroxyapatite nanoparticles as phosphorus fertilizer in Andisols and Oxisols. Soil Sci. Soc. Am. J. 79(2), 551-558.

Murphy, J., Riley, J.P., 1962. A modified single solution method for the determination of phosphate in natural waters. Anal. Chem. Acta 27, 31-36.

Mylon, S.E., Chen, K.L., Elimelech, M., 2004. Influence of natural organic matter and ionic composition on the kinetics and structure of hematite colloid sggregation: Implications to iron depletion in estuaries. Langmuir 20(21), 9000-9006.

Nabiul Afrooz, A.R.M., Khan, I.A., Hussain, S.M., Saleh, N.B., 2013. Mechanistic heteroaggregation of gold nanoparticles in a wide range of solution chemistry. Environ. Sci. Technol. 47(4), 1853-1860.

Navrotsky, A., Mazeina, L., Majzlan, J., 2008. Size-driven structural and thermodynamic complexity in iron oxides. Science 319(5870), 1635-1638.

Paytan, A., Kolodny, Y., Neori, A., Luz, B., 2002. Rapid biologically mediated oxygen isotope exchange between water and phosphate. Global Biogeochem. Cy. 16(1).

DOI:10.1029/2001GB001430.

Petosa, A.R., Jaisi, D.P., Quevedo, I.R., Elimelech, M., Tufenkji, N., 2010. Aggregation and deposition of engineered nanomaterials in aquatic environments: Role of physicochemical interactions. Environ. Sci. Technol. 44(17), 6532-6549.

Praetorius, A., Labille, J., Scheringer, M., Thill, A., Hungerbuhler, K., Bottero, J.Y., 2014. Hetero-aggregation of titanium dioxide nanoparticles with model natural colloids under environmentally relevant conditions. Environ. Sci. Technol. 48(18), 10690-10698. 
Roco, M.C., Bainbridge, W.S., 2013. The new world of discovery, invention, and innovation: Convergence of knowledge, technology, and society. J. Nanopart. Res. 15, 1946.

Schijven, J.F., Hassanizadeh, S.M., 2000. Removal of viruses by soil passage: Overview of modeling, processes, and parameters. Crit. Rev. Environ. Sci. Technol. 30(1), 49-127.

Schwertmann, U., Cornell, R.M., 2000. Iron Oxides in the Laboratory: Preparation and Characterization, Second Edition. WILEY-VCH Verlag GmbH.

Shen, C., Wang, H., Lazouskaya, V., Du, Y., Lu, W., Wu, J., Zhang, H., Huang, Y., 2015. Cotransport of bismerthiazol and montmorillonite colloids in saturated porous media. J. Contam. Hydrol. 177-178, 18-29.

Shevchenko, E.V., Talapin, D.V., Kotov, N.A., O’Brien, S., Murray, C.B., 2006. Structural diversity in binary nanoparticle superlattices. Nature 439, 55-59.

Sigg, L., Stumm, W., 2011. Aquatische Chemie, fifth ed. vdf/UTB, Zurich.

Sims, J.T., Simard, R.R., Joern, B.C., 1998. Phosphorus loss in agricultural drainage: Historical perspective and current research. J. Environ. Qual. 27(2), 277-293.

Simunek, J., Sejna, M., Saito, H., Sakai, M., van Genuchten, M.T., 2013. The Hydrus-1D Software Package for Simulating the Movement of Water, Heat, and Multiple Solutes in Variably Saturated Media. Version 4.17, HYDRUS Software Series 3, Department of Environmental Sciences, University of California Riverside, Riverside, CA.

Simunek, J., van Genuchten, M.T., Sejna, M., Toride, N., Leij, F.J., 1999. The STANMOD computer software for evaluating solute transport in porous media using analytical solutions of convection-dispersion equation. Versions 1.0 and 2.0, IGWMC - TPS - 71 International Ground Water Modeling Center, Colorado School of Mines, Golden, Colorado, 32pp. 
Skulan, J.L., Beard, B.L., Johnson, C.M., 2002. Kinetic and equilibrium Fe isotope fractionation between aqueous Fe(III) and hematite. Geochim. Cosmochim. Acta 66(17), 2995-3015.

Steefel, C.I., Van Cappellen, P., 1990. A new kinetic approach to modeling water-rock interaction: The role of nucleation, precursors, and Ostwald ripening. Geochim. Cosmochim. Acta 54(10), 2657-2677.

Stoffregen, R., 1996. Numerical simulation of mineral-water isotope exchange via Ostwald ripening. Am. J. Sci. 296(8), 908-931.

Stout, L.M., Joshi, S.R., Kana, T., Jaisi, D.P. 2014. Microbial activities and phosphorus cycling: an application of oxygen isotope ratios in phosphate. Geochim. Cosmochim. Acta 138, 101-116.

Stumm, W., Morgan, J.J., 1996. Aquatic Chemistry. 3rd ed. New York: Wiley-Intescience.

Stumm, W., Sulzberger, B., 1991. The cycling of iron in natural environments: Considerations based on laboratory studies of heterogeneous redox processes. Geochim. Cosmochim. Acta 56(8), 3233-3257.

Su, C., Puls, R.W., Krug, T.A., Watling, M.T., O’Hara, S.K., Quinn, J.W., Ruiz, N.E., 2012. A two and half-year-performance evaluation of a field test on treatment of source zone tetrachloroethene and its chlorinated daughter products using emulsified zero valent iron nanoparticles. Water Res. 46(16), 5071-5084.

Tipping, E. and Higgins, D.C., 1982. The effect of adsorbed humic substances on the colloid stability of haematite particles. Colloid Surface 5(2), 85-92.

Tufenkji, N., Elimelech, M., 2005. Breakdown of colloid filtration theory: Role of the secondary energy minimum and surface charge heterogeneities. Langmuir 21(3), 841-852. 
van der Zee, C., Roberts, D.R., Rancourt, D.G., Slomp, C.P., 2003. Nanogoethite is the dominant reactive oxyhydroxide phase in lake and marine sediments. Geology 31(11), 993-996.

Vennemann, T.W., Fricke, H.C., Blake, R.E., O’Neil, J.R., Colman, A., 2002. Oxygen isotope analysis of phosphates: A comparison of techniques for analysis of $\mathrm{Ag}_{3} \mathrm{PO}_{4}$. Chem. Geol. 185(3-4), 321-336.

Verwey, E.J.W., Overbeek, J.T.G., 1948. Theory of the Stability of Lyophobic Colloids. Elsevier, Amsterdam.

Wang, D., Bradford, S.A., Harvey, R.W., Gao, B., Cang, L., Zhou, D., 2012a. Humic acid facilitates the transport of ARS-labeled hydroxyapatite nanoparticles in iron oxyhydroxide-coated sand. Environ. Sci. Technol. 46(5), 2738-2745.

Wang, D., Bradford, S.A., Paradelo, M., Peijnenburg, W.J.G.M., Zhou, D., 2012b. Facilitated transport of copper with hydroxyapatite nanoparticles in saturated sand. Soil Sci. Soc. Am. J. 76(2), 375-388.

Wang, D., Ge, L., He, J., Zhang, W., Jaisi, D.P., Zhou, D., 2014a. Hyperexponential and nonmonotonic retention of polyvinylpyrrolidone-coated silver nanoparticles in an Ultisol. J. Contam. Hydrol. 164, 35-48.

Wang, D., Su, C., Zhang, W., Hao, X., Cang, L., Wang, Y., Zhou, D., 2014b. Laboratory assessment of the mobility of water-dispersed engineered nanoparticles in a red soil (Ultisol). J. Hydrol. 519, 1677-1687.

Wang, D., Jin, Y., Jaisi, D.P., 2015a. Effect of size-selective retention on the cotransport of hydroxyapatite and geothite nanoparticles in saturated porous media. Environ. Sci. Technol. 49 (14), 8461-8470. 
Wang, D., Jaisi, D.P., Yan, J., Jin, Y., Zhou, D.M., 2015b. Transport and retention of polyvinylpyrrolidone-coated silver nanoparticles in natural soils. Vadose Zone J. 14 (7), DOI:10.2136/vzj2015.01.0007.

Watson, E.B., Muller, T., 2009. Non-equilibrium isotopic and elemental fractionation during diffusion-controlled crystal growth under static and dynamic conditions. Chem. Geol. 267(3-4), 111-124.

Waychunas, G.A., Kim, C.S., Banfield, J.F., 2005. Nanoparticulate iron oxide minerals in soils and sediments: Unique properties and contaminant scavenging mechanisms. J. Nanopart. Res. 7(4-5), 409-433.

White, A.F., Brantley, S.L., 1995. Chemical weathering of silicate minerals. Rev. Mineral. 31, 1583.

Yao, K.M., Habibian, M.M., O’Melia, C.R., 1971. Water and waste water filtration: Concepts and applications. Environ. Sci. Technol. 5(11), 1105-1112.

Zhang, Z., Li, M., Chen, W., Zhu, S., Liu, N., Zhu, L., 2010. Immobilization of lead and cadmium from aqueous solution and contaminated sediment using nano-hydroxyapatite. Environ. Pollut. 158(2), 514-519.

Zhao, J., Liu, F., Wang, Z., Cao, X., Xing, B., 2015. Hetero-aggregation of graphene oxide with minerals in aqueous phase. Environ. Sci. Technol. 49(5), 2849-2857.

Zhu, S.H., Huang, B.Y., Zhou, K.C., Huang, S.P., Liu, F., Li, Y.M., Xue, Z.G., Long, Z.G., 2004. Hydroxyapatite nanoparticles as a novel gene carrier. J. Nanopart. Res. 6(2), 307-311. 
Table 1. Physicochemical properties and mass recovery percentages for column experiments under different experimental conditions.

\begin{tabular}{|c|c|c|c|c|c|c|c|c|c|}
\hline \multirow[t]{3}{*}{$\mathrm{pH}$} & \multirow{3}{*}{$\begin{array}{l}\mathrm{IS}^{\mathrm{a}} \\
(\mathrm{mM})\end{array}$} & \multirow{3}{*}{$\begin{array}{c}q^{\mathrm{b}} \\
\left(\mathrm{cm} \min ^{-1}\right)\end{array}$} & \multirow{3}{*}{$\begin{array}{l}\text { SRHA }^{\mathrm{c}} \\
\left(\mathrm{mg} \mathrm{L}^{-1}\right)\end{array}$} & \multicolumn{6}{|c|}{ Recovery (\%) } \\
\hline & & & & \multicolumn{3}{|c|}{ HANPs } & \multicolumn{3}{|c|}{ Hematite } \\
\hline & & & & $M_{\text {eff }}^{\mathrm{d}}$ & $M_{\mathrm{ret}}^{\mathrm{e}}$ & $M_{\mathrm{tot}}^{\mathrm{f}}$ & $M_{\text {eff }}{ }^{d}$ & $M_{\text {ret }}{ }^{\mathrm{e}}$ & $M_{\text {tot }}{ }^{f}$ \\
\hline 6.5 & 0.1 & 0.44 & & 38.9 & 55.0 & 93.9 & 2.65 & 108 & 111 \\
\hline 7.5 & 0.1 & 0.44 & & 5.67 & 93.3 & 99.0 & 3.77 & 97.5 & 101 \\
\hline 10.5 & 0.1 & 0.44 & & 93.2 & 13.8 & 107 & 89.0 & 9.30 & 98.3 \\
\hline 7.5 & 0.1 & 0.44 & 1 & 77.8 & 5.27 & 83.1 & 97.1 & 1.13 & 98.2 \\
\hline 7.6 & 10 & 0.44 & 1 & 42.1 & 55.4 & 97.5 & 62.4 & 35.4 & 97.8 \\
\hline 7.6 & 50 & 0.44 & 1 & 11.1 & 88.1 & 99.2 & 11.3 & 86.5 & 97.8 \\
\hline 7.5 & 0.1 & 0.22 & & 2.54 & 99.9 & 102 & 1.53 & 100 & 102 \\
\hline 7.5 & 0.1 & 0.044 & & 1.15 & 108 & 109 & 0.38 & 101 & 101 \\
\hline
\end{tabular}

${ }^{a}$ Ionic strength. ${ }^{b}$ Darcy velocity. ${ }^{\mathrm{c}}$ Suwannee River humic acid. ${ }^{\mathrm{d}, \mathrm{e} \text {, and f }}$ Effluent, retentate, and total percentages of HANPs (or hematite) recovered from column experiments, respectively. 
Table 2. Electrokinetic properties of HANPs-hematite influents, quartz sands, and individual HANPs suspensions under different experimental conditions.

\begin{tabular}{|c|c|c|c|c|c|c|}
\hline \multirow[t]{2}{*}{$\mathrm{pH}$} & \multirow{2}{*}{$\begin{array}{c}\text { IS } \\
(\mathrm{mM})\end{array}$} & \multirow{2}{*}{$\begin{array}{c}q \\
\left(\mathrm{~cm} \mathrm{~min}{ }^{-1}\right)\end{array}$} & \multirow{2}{*}{$\begin{array}{c}\text { SRHA } \\
\left(\mathrm{mg} \mathrm{L}^{-1}\right)\end{array}$} & \multicolumn{3}{|c|}{ Zeta potential $(\mathrm{mV})$} \\
\hline & & & & $\zeta_{\text {influent }}{ }^{\mathrm{a}}$ & $\zeta_{\text {sand }} \mathrm{b}$ & $\zeta_{\text {HANPs }}{ }^{c}$ \\
\hline 6.5 & 0.1 & 0.44 & & $0.32 \pm 0.13 \mathrm{a}$ & $-20.7 \pm 1.2 \mathrm{a}$ & $-22.1 \pm 0.78 \mathrm{a}$ \\
\hline 7.5 & 0.1 & 0.44 & & $-3.21 \pm 0.66 b$ & $-21.3 \pm 1.4 \mathrm{a}$ & $-26.3 \pm 0.59 b$ \\
\hline 10.5 & 0.1 & 0.44 & & $-23.1 \pm 2.4 \mathrm{c}$ & $-43.6 \pm 1.2 b$ & $-31.1 \pm 1.6 \mathrm{c}$ \\
\hline 7.5 & 0.1 & 0.44 & 1 & $-15.6 \pm 2.5 \mathrm{a}$ & $-25.3 \pm 2.1 \mathrm{a}$ & $-29.6 \pm 0.83 a$ \\
\hline 7.6 & 10 & 0.44 & 1 & $-11.1 \pm 1.1 b$ & $-15.3 \pm 0.81 b$ & $-25.1 \pm 1.0 \mathrm{~b}$ \\
\hline 7.6 & 50 & 0.44 & 1 & $-5.72 \pm 0.15 c$ & $-4.37 \pm 1.8 c$ & $-18.9 \pm 0.75 c$ \\
\hline 7.5 & 0.1 & 0.22 & & $-3.21 \pm 0.66 b$ & $-21.3 \pm 1.4 \mathrm{a}$ & $-26.3 \pm 0.59 b$ \\
\hline 7.5 & 0.1 & 0.044 & & $-3.21 \pm 0.66 b$ & $-21.3 \pm 1.4 \mathrm{a}$ & $-26.3 \pm 0.59 b$ \\
\hline
\end{tabular}

a, b, and $c_{\zeta}$-potentials of HANPs-hematite influents, quartz sands, and individual HANPs suspensions, respectively. Mean values \pm standard deviations in each vertical column followed by the same lowercase letters are not significantly different using Tukey's HSD test at $p<0.05$. 
Table 3. Average hydrodynamic diameters $\left(D_{\mathrm{H}}\right)$ of HANPs-hematite samples in the influents, effluents, and retentates in the column at different depths, and $D_{\mathrm{H}}$ of individual HANPs under different experimental conditions.

\begin{tabular}{|c|c|c|c|c|c|c|c|c|c|c|}
\hline \multirow[t]{3}{*}{$\mathrm{pH}$} & \multirow{3}{*}{$\begin{array}{c}\mathrm{IS} \\
(\mathrm{mM})\end{array}$} & \multirow{3}{*}{$\begin{array}{c}q \\
\left.(\mathrm{~cm} \mathrm{~min})^{-1}\right)\end{array}$} & \multirow{3}{*}{$\begin{array}{c}\text { SRHA } \\
\left(\mathrm{mg} \mathrm{L}^{-1}\right)\end{array}$} & \multicolumn{6}{|c|}{$D_{\mathrm{H}}$ of HANPs-hematite sample $(\mathrm{nm})$} & \multirow{3}{*}{$\begin{array}{c}D_{\mathrm{H}} \text { of HANPs } \\
\quad(\mathrm{nm})\end{array}$} \\
\hline & & & & \multirow[t]{2}{*}{ Influent } & \multirow[t]{2}{*}{ Effluent } & \multicolumn{4}{|c|}{ Retentate (nm) } & \\
\hline & & & & & & $0-1$ & $1-2$ & $2-3$ & $3-4$ & \\
\hline 6.5 & 0.1 & 0.44 & & $1283 \pm 248 \mathrm{a}$ & $669 \pm 46 a$ & $1863 \pm 81 \mathrm{a}$ & $1473 \pm 103 \mathrm{a}$ & $1406 \pm 379 \mathrm{a}$ & $742 \pm 189 a$ & $1021 \pm 192 \mathrm{a}$ \\
\hline 7.5 & 0.1 & 0.44 & & $958 \pm 263 b$ & $675 \pm 72 \mathrm{a}$ & $1776 \pm 111 \mathrm{a}$ & $1402 \pm 157 \mathrm{a}$ & $1269 \pm 43 \mathrm{a}$ & $758 \pm 32 \mathrm{a}$ & $907 \pm 80 \mathrm{a}$ \\
\hline 10.5 & 0.1 & 0.44 & & $635 \pm 101 \mathrm{c}$ & $220 \pm 10 b$ & $1323 \pm 115 b$ & $827 \pm 174 \mathrm{~b}$ & $537 \pm 114 \mathrm{~b}$ & $310 \pm 31 b$ & $274 \pm 12 b$ \\
\hline 7.5 & 0.1 & 0.44 & 1 & $181 \pm 17 \mathrm{a}$ & $180 \pm 3.6 \mathrm{a}$ & $437 \pm 188$ a & $403 \pm 142 \mathrm{a}$ & $335 \pm 67 \mathrm{a}$ & $342 \pm 41 \mathrm{a}$ & $272 \pm 14 \mathrm{a}$ \\
\hline 7.6 & 10 & 0.44 & 1 & $624 \pm 24 b$ & $473 \pm 41 \mathrm{~b}$ & $823 \pm 36 b$ & $693 \pm 42 b$ & $601 \pm 139 \mathrm{~b}$ & $641 \pm 34 b$ & $324 \pm 13 b$ \\
\hline 7.6 & 50 & 0.44 & 1 & $747 \pm 149 \mathrm{bc}$ & $616 \pm 70 c$ & $945 \pm 22 c$ & $703 \pm 35 b$ & $723 \pm 56 b$ & $604 \pm 85 b$ & $452 \pm 30 c$ \\
\hline 7.5 & 0.1 & 0.22 & & $958 \pm 263 b$ & $890 \pm 55 b$ & $1884 \pm 81 \mathrm{a}$ & $1442 \pm 54 \mathrm{a}$ & $1351 \pm 38 b$ & $809 \pm 85 \mathrm{ab}$ & $907 \pm 80 \mathrm{a}$ \\
\hline 7.5 & 0.1 & 0.044 & & $958 \pm 263 b$ & $1033 \pm 64 c$ & $1843 \pm 38 \mathrm{a}$ & $1474 \pm 44 \mathrm{a}$ & $1041 \pm 49 \mathrm{c}$ & $680 \pm 72 \mathrm{ab}$ & $907 \pm 80 a$ \\
\hline
\end{tabular}

Mean values \pm standard deviations in each vertical column followed by the same lowercase letters are not significantly different using Tukey's HSD test at $p<0.05$. 


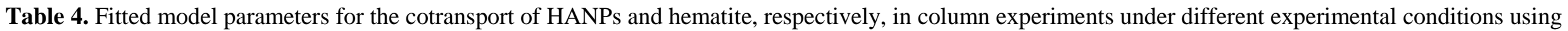
the one-site kinetic attachment model or the ripening model.

\begin{tabular}{|c|c|c|c|c|c|c|c|c|c|c|c|c|c|c|c|c|c|}
\hline \multirow[t]{3}{*}{$\mathrm{pH}$} & \multirow{3}{*}{$\begin{array}{c}\text { IS } \\
(\mathrm{mM})\end{array}$} & \multirow{3}{*}{$\begin{array}{c}q \\
\left.(\mathrm{~cm} \mathrm{~min})^{-1}\right)\end{array}$} & \multirow{3}{*}{$\begin{array}{l}\text { SRHA } \\
\left(\mathrm{mg} \mathrm{L}^{-1}\right)\end{array}$} & \multicolumn{7}{|c|}{ HANPs } & \multicolumn{7}{|c|}{ Hematite } \\
\hline & & & & \multicolumn{3}{|c|}{ One-site model } & \multicolumn{3}{|c|}{ Ripening model } & \multirow[t]{2}{*}{$R^{2 \mathrm{~g}}$} & \multicolumn{3}{|c|}{ One-site model } & \multicolumn{3}{|c|}{ Ripening model } & \multirow[t]{2}{*}{$R^{2}$} \\
\hline & & & & $S_{\max } / C_{\mathrm{o}}{ }^{\mathrm{a}}$ & $k_{\mathrm{a}}^{\mathrm{b}}$ & $\beta^{\mathrm{c}}$ & $k_{\text {int }}{ }^{\mathrm{d}}$ & $k_{\mathrm{d}}^{\mathrm{e}}$ & $k_{\mathrm{r}}^{\mathrm{f}}$ & & $S_{\max } / C_{\mathrm{o}}$ & $k_{\mathrm{a}}$ & $\beta$ & $k_{\text {int }}$ & $k_{\mathrm{d}}$ & $k_{\mathrm{r}}$ & \\
\hline 6.5 & 0.1 & 0.44 & & 5.31 & 1.96 & 0.659 & & & & 0.858 & & & & -0.228 & 0.470 & $2.68 \mathrm{E}-4$ & 0.966 \\
\hline 7.5 & 0.1 & 0.44 & & & & & -0.208 & 0.437 & $4.88 \mathrm{E}-3$ & 0.920 & & & & -0.248 & 0.407 & $3.51 \mathrm{E}-4$ & 0.990 \\
\hline 10.5 & 0.1 & 0.44 & & 0.560 & 76.9 & 2.28 & & & & 0.963 & 0.221 & 31.2 & 1.69 & & & & 0.955 \\
\hline 7.5 & 0.1 & 0.44 & 1 & 0.183 & 25.5 & 1.33 & & & & 0.915 & $5.87 \mathrm{E}-2$ & 7.94 & 0.764 & & & & 0.955 \\
\hline 7.6 & 10 & 0.44 & 1 & & & & -0.232 & $9.22 \mathrm{E}-2$ & $5.39 \mathrm{E}-3$ & 0.943 & & & & -0.272 & $4.04 \mathrm{E}-2$ & $6.84 \mathrm{E}-3$ & 0.932 \\
\hline 7.6 & 50 & 0.44 & 1 & & & & -0.135 & 0.326 & $3.43 \mathrm{E}-3$ & 0.999 & & & & -0.121 & 0.314 & $2.27 \mathrm{E}-3$ & 1.00 \\
\hline 7.5 & 0.1 & 0.22 & & & & & $-3.78 \mathrm{E}-2$ & 0.271 & $1.61 \mathrm{E}-4$ & 0.907 & & & & -0.137 & 0.270 & $1.17 \mathrm{E}-4$ & 0.994 \\
\hline 7.5 & 0.1 & 0.044 & & & & & $-5.11 \mathrm{E}-3$ & $6.90 \mathrm{E}-2$ & $3.95 \mathrm{E}-5$ & 0.937 & & & & $-5.54 \mathrm{E}-2$ & $6.96 \mathrm{E}-2$ & $4.29 \mathrm{E}-5$ & 0.994 \\
\hline
\end{tabular}

${ }^{a}$ Normalized maximum solid-phase concentration of retained particles $\left[\mathrm{cm}^{3} \mathrm{~g}^{-1}\right] .{ }^{b}$ First-order attachment rate coefficient $\left[\mathrm{min}^{-1}\right] \cdot{ }^{\mathrm{c}}$ An empirical parameter controlling the shape of the spatial distribution of retained particles $[-] .{ }^{d}$ Particle interaction rate coefficient $\left[\mathrm{cm}^{3}\right.$ $\left.\min ^{-1} \mathrm{~N}^{-1}\right] .{ }^{\mathrm{e}}$ Particle deposition rate coefficient $\left[\mathrm{min}^{-1}\right] .{ }^{\mathrm{f}}$ Particle release rate coefficient $\left[\mathrm{min}^{-1}\right] .{ }^{\mathrm{g}}$ Squared Pearson's correlation coefficient. 

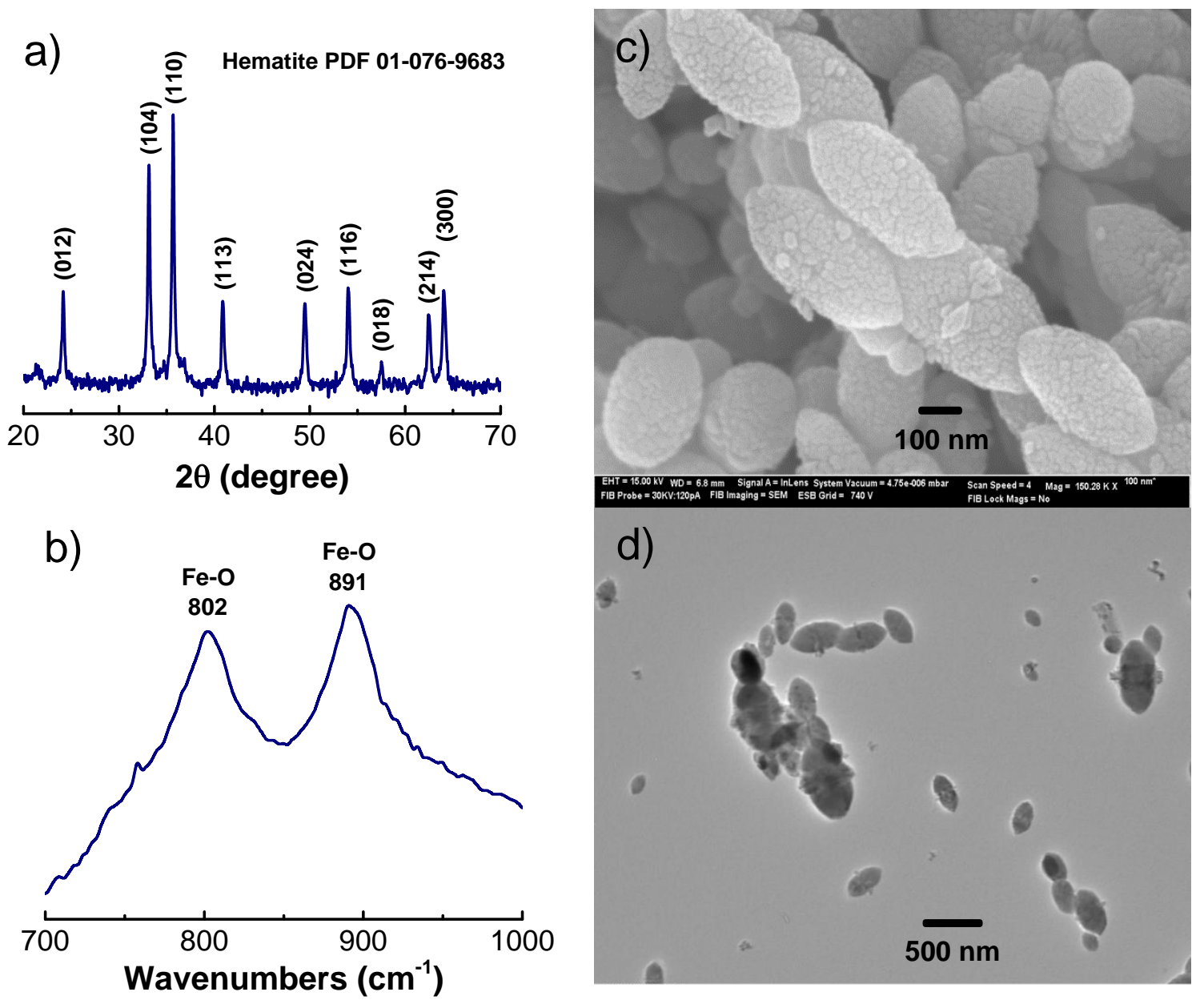

38911 Fig. 1.Powder XRD pattern (a), FTIR spectrum (b), SEM image (c), and TEM image (d) of the 39

912 hematite.The scale bars in (c, d) are 100 and $500 \mathrm{~nm}$, respectively. 


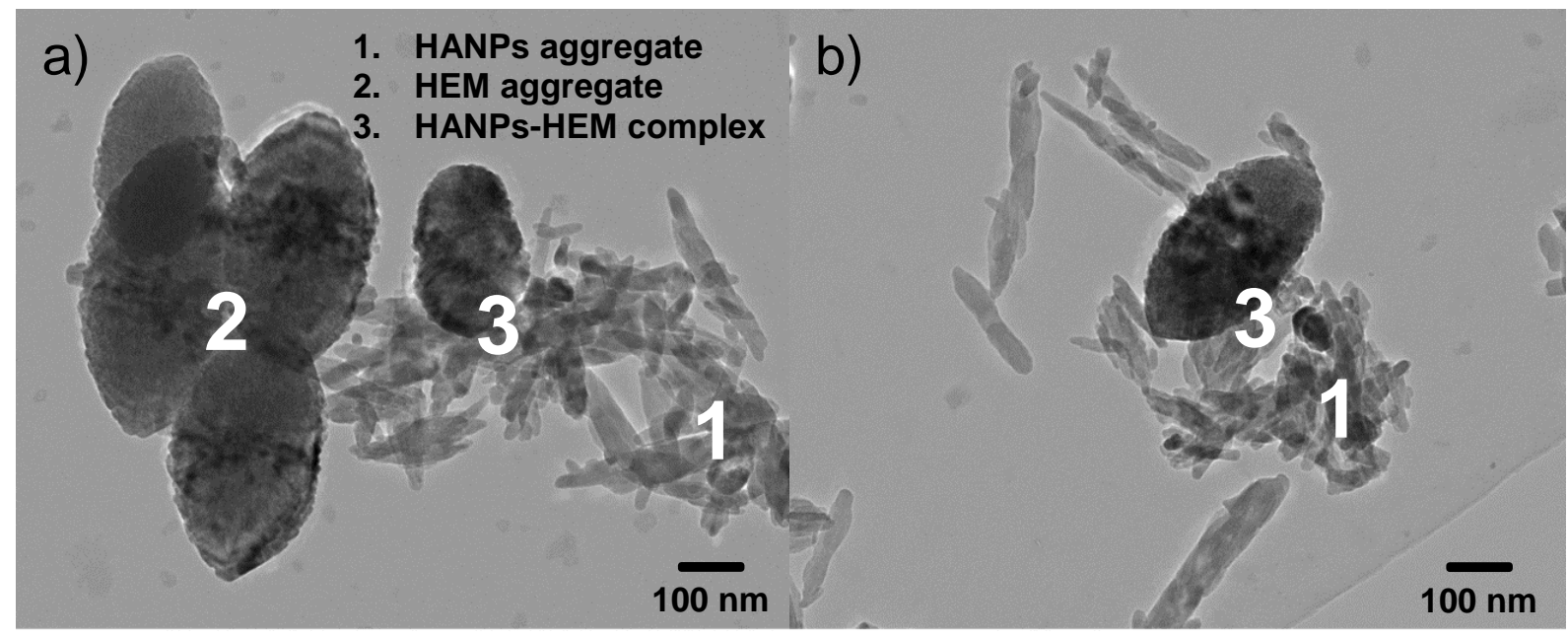

Fig. 2. TEM images of the HANPs-hematite influent at $\mathrm{pH} 7.5$. The scale bar in (a, b) is $100 \mathrm{~nm}$.

25

26916 At pH 7.5, the negatively charged HANPs readily sorb onto the positively charged hematite via 27 28 

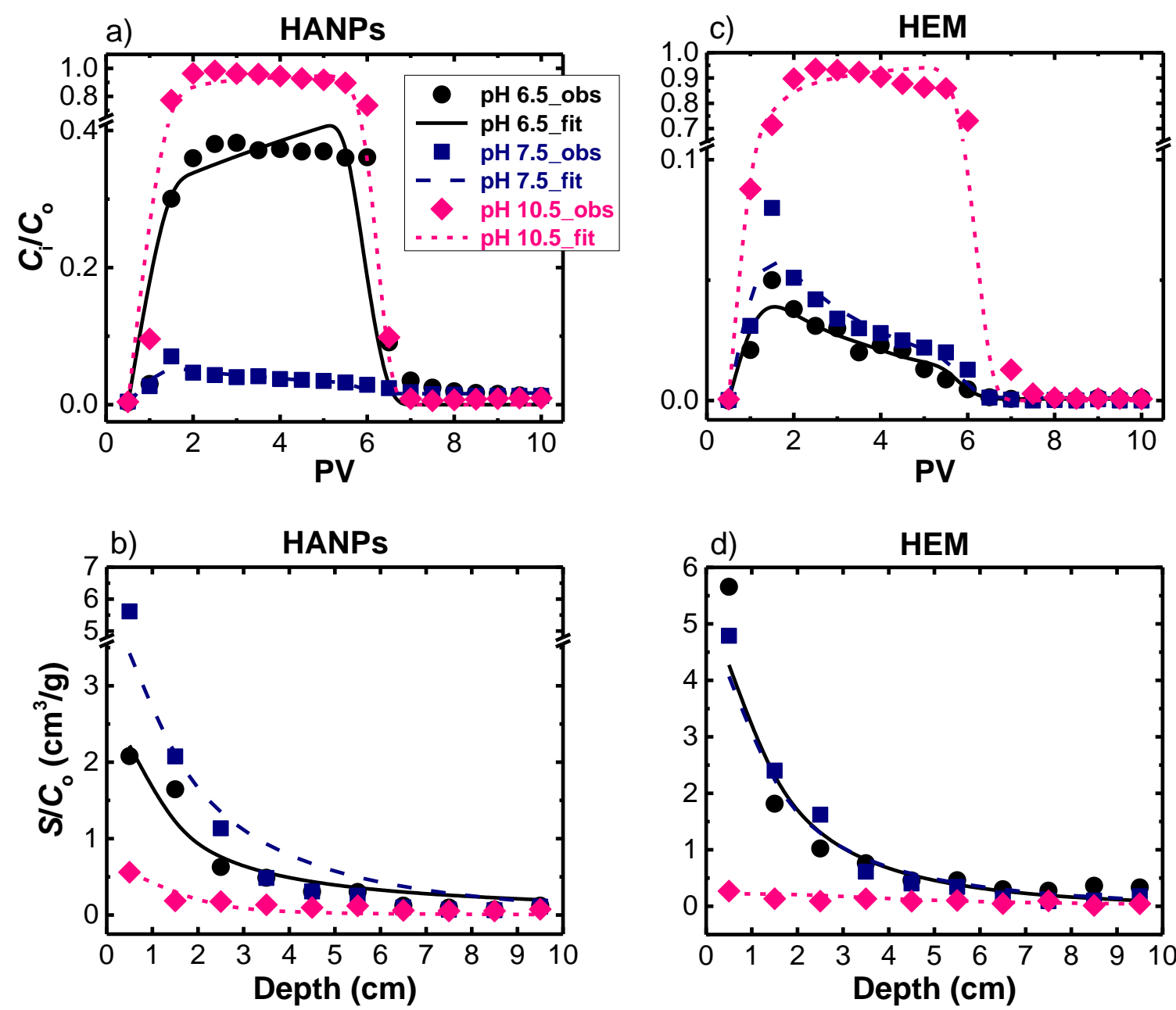

920 Fig. 3.pH effect: observed and fitted cotransport breakthrough curves (a, c) and retention profiles

921 (b, d) of HANPs (a, b) and hematite (c, d), respectively, at varying pHs $(6.5,7.5$, and 10.5) when

922 IS $=0.1 \mathrm{mM} \mathrm{KNO}_{3}$ and $q=0.44 \mathrm{~cm} \mathrm{~min}^{-1}$. Note different scales in $y$-axes. The blocking

923 breakthrough curves were simulated using the one-site kinetic attachment model, whereas the 924 ripening model was used to fit the ripening breakthrough curves.

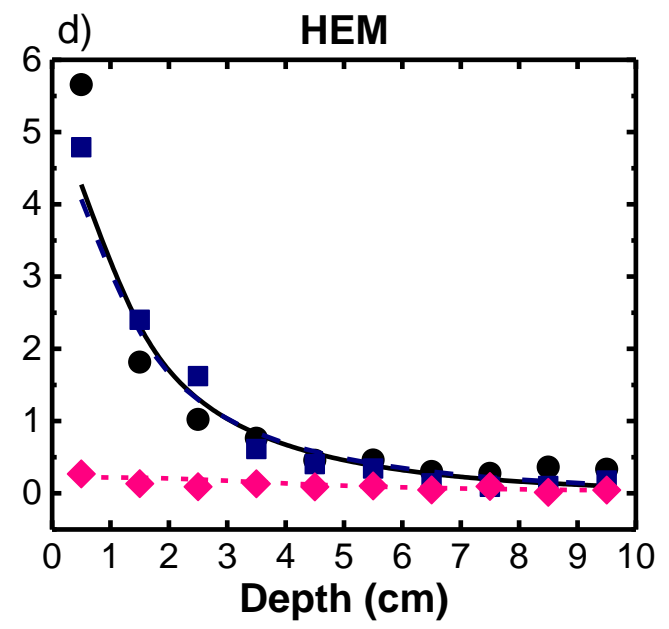



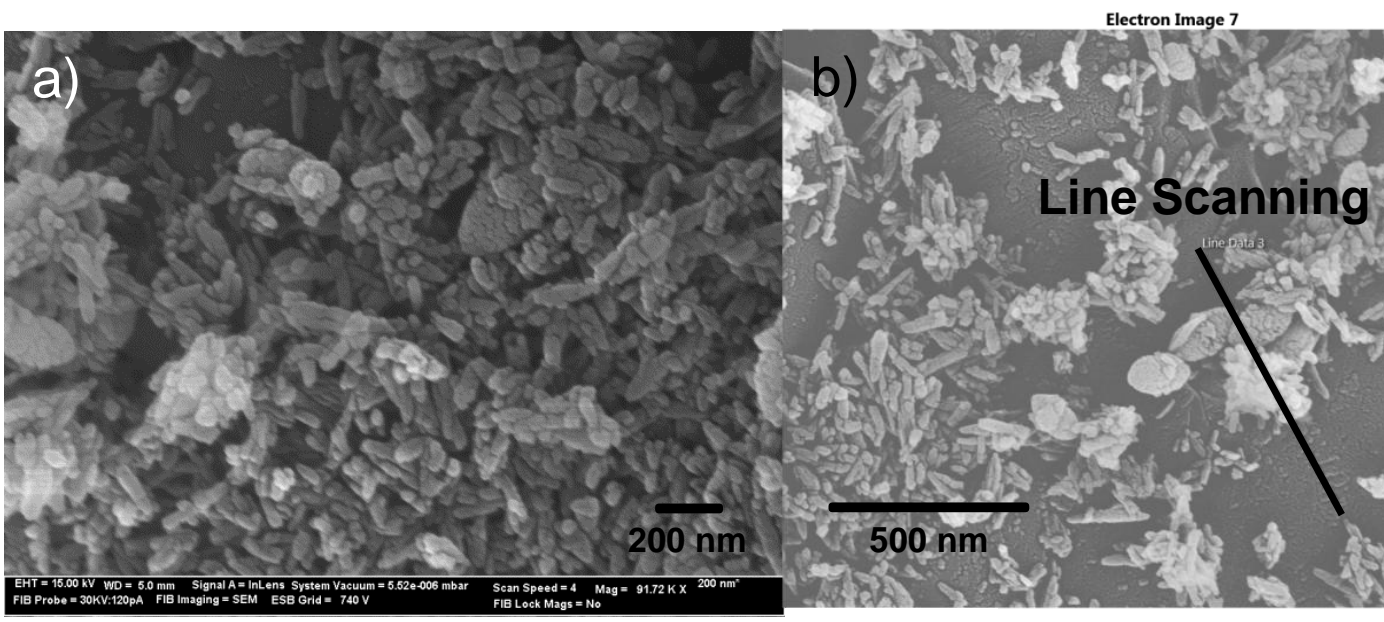

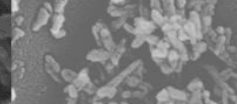

Line Scanning

927 Fig. 4. (a, b) SEM images of HANPs aggregates, hematite aggregates, and HANPs-hematite

928 complexes retained on the sand grains that were excavated from the column inlet $(0-1 \mathrm{~cm})$ after

929 completion of the cotransport of HANPs and hematite at $\mathrm{pH} 7.5, \mathrm{IS}=0.1 \mathrm{mM} \mathrm{KNO}$, and $q=$ $930 \quad 0.44 \mathrm{~cm} \mathrm{~min}^{-1}$. (c) The corresponding energy-dispersive X-ray (EDX) spectrum of the retained 931 HANPs-hematite complexes (b) on the sand grain based upon the line scanning technique. The 932 scale bars in (a, b) are 200 and $500 \mathrm{~nm}$, respectively. 

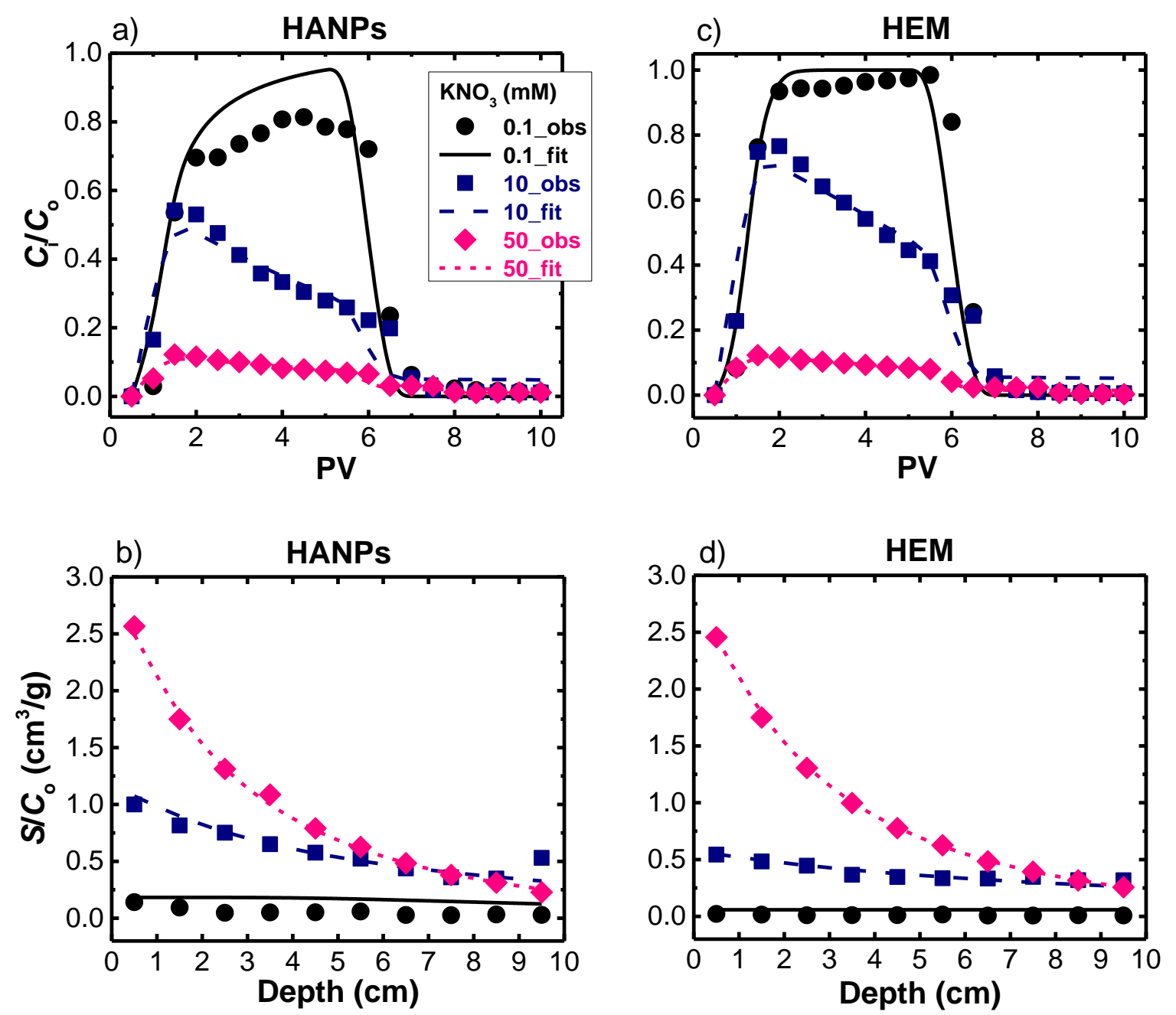

935 Fig. 5. IS effect: observed and fitted cotransport breakthrough curves (a, c) and retention profiles 936 (b, d) of HANPs $(\mathrm{a}, \mathrm{b})$ and hematite $(\mathrm{c}, \mathrm{d})$, respectively, under ISs of $0.1,10$, and $50 \mathrm{mM} \mathrm{KNO}_{3}$ 937 in the presence of $1 \mathrm{mg} \mathrm{L}^{-1}$ SRHA at $\mathrm{pH} \sim 7.5$ and $q=0.44 \mathrm{~cm} \mathrm{~min}^{-1}$. in the presence of $1 \mathrm{mg} \mathrm{L}^{-1}$ SRHA at $\mathrm{pH} \sim 7.5$ and $q=0.44 \mathrm{~cm} \mathrm{~min}^{-1}$. 

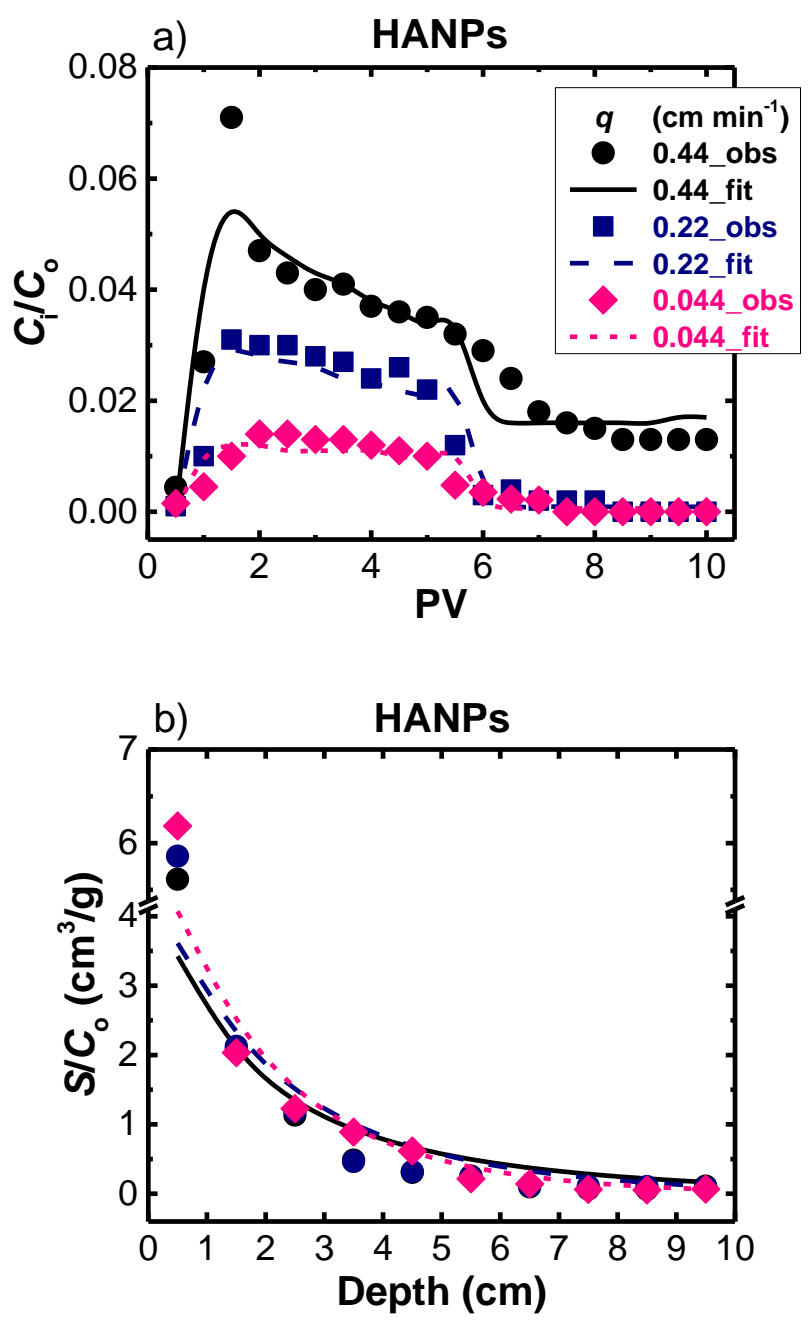
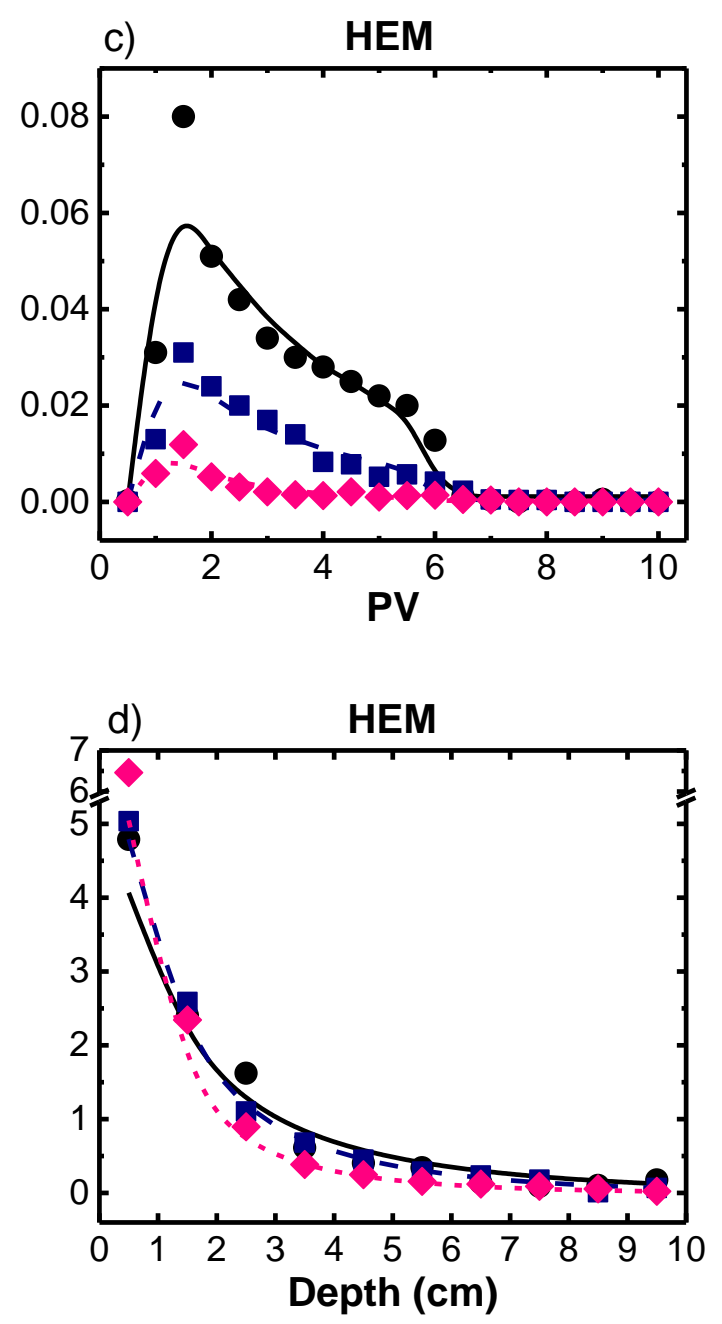

940 Fig. 6. Flow rate effect: observed and fitted cotransport breakthrough curves (a, c) and retention

941 profiles $(b, d)$ of HANPs $(a, b)$ and hematite $(c, d)$, respectively, under $q$ of $0.44,0.22$, and 0.044

$942 \mathrm{~cm} \mathrm{~min}^{-1}$ at $\mathrm{pH} 7.5$ and $\mathrm{IS}=0.1 \mathrm{mM} \mathrm{KNO}_{3}$. 


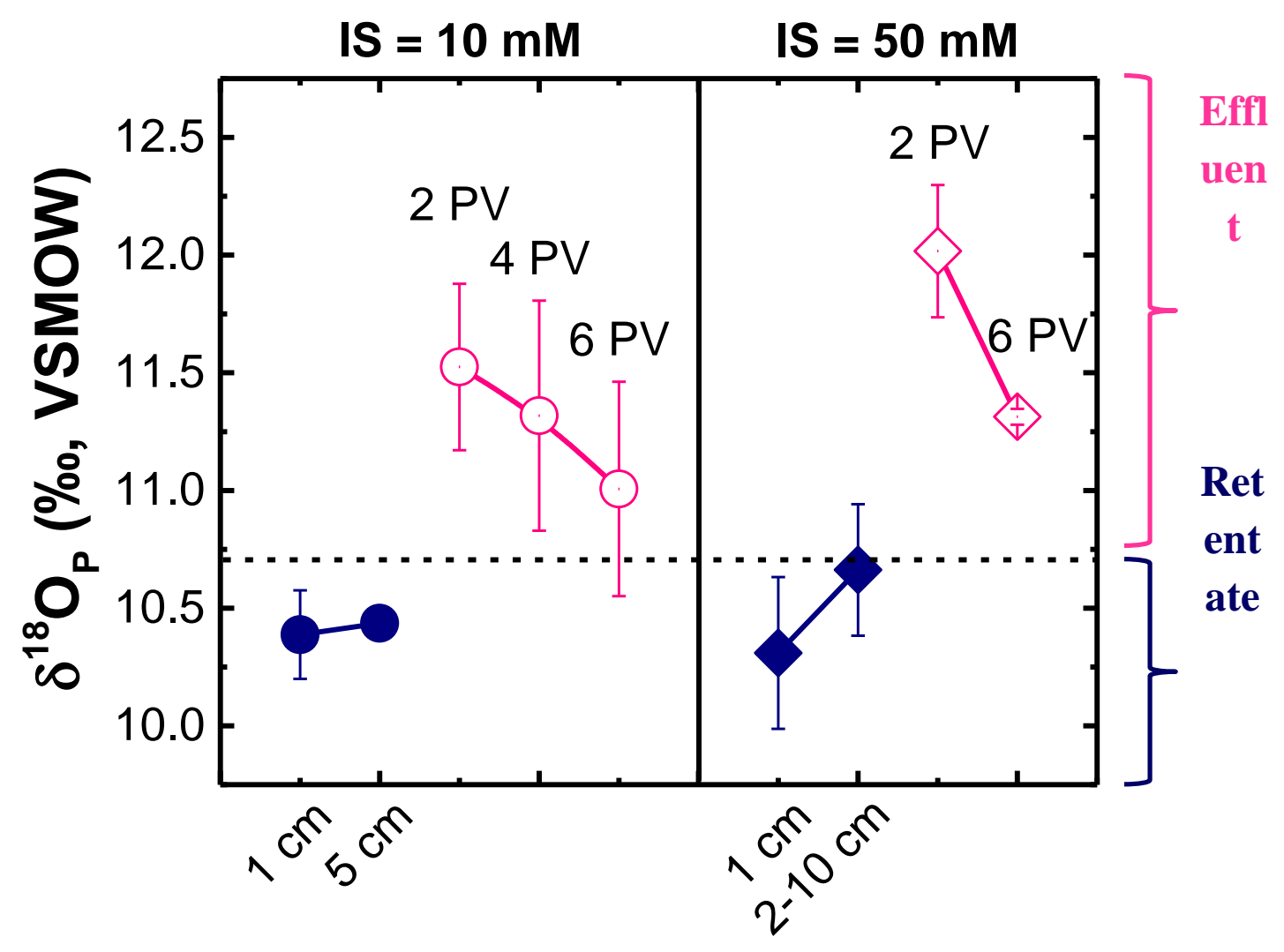

Fig. 7. Effect of IS on isotope fractionation: shown are the $\delta^{18} \mathrm{O}_{\mathrm{P}}$ values of HANPs in the influent, 946 effluent (e.g., 2, 4, and 6 PV), and retentate samples at different depths (e.g., 1, 5, and 2-10 cm) 947 at two ISs, 10 and $50 \mathrm{mM} \mathrm{KNO}_{3}$, respectively. All column experiments were conducted at $\mathrm{pH}$ $948 \sim 7.5$ and $q=0.44 \mathrm{~cm} \mathrm{~min}^{-1}$ in the presence of $1 \mathrm{mg} \mathrm{L}^{-1}$ SRHA. The $\delta^{18} \mathrm{O}_{\mathrm{P}}$ value of the HANPs 949 starting (influent) suspension was $10.70 \%$ (shown by the dotted line). Standard deviation was 950 calculated using $\delta^{18} \mathrm{O}_{\mathrm{P}}$ values obtained from independent column experiments. The solid lines 951 are the trends of isotope fractionation but not fitting results.

95

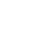
(1)

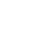
( 3 


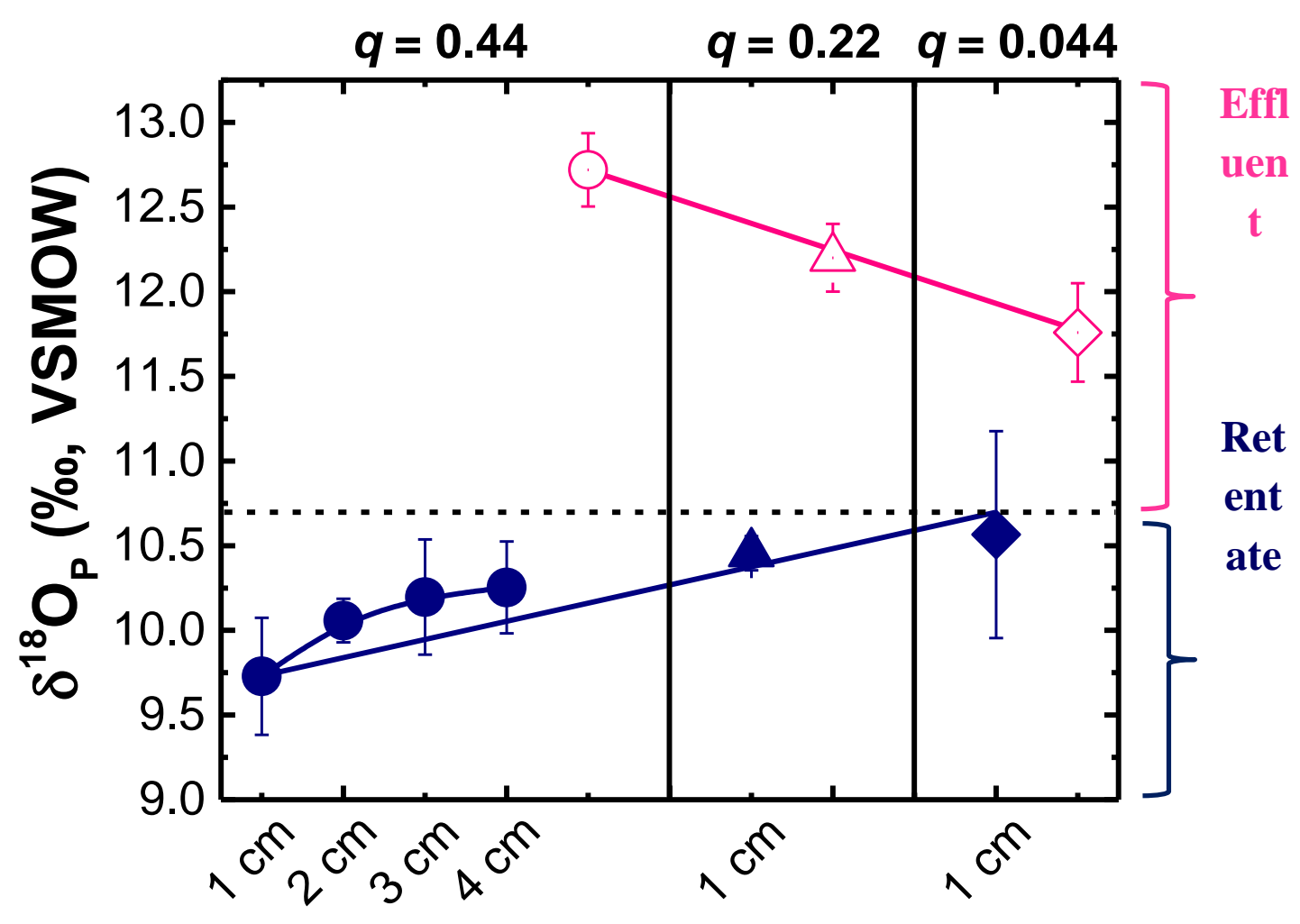

954 Fig. 8. Effect of flow rate on isotope fractionation: shown are the $\delta^{18} \mathrm{O}_{\mathrm{P}}$ values of HANPs in the 955 influent, effluent, and retentate samples at different depths (e.g., 1, 2, 3, and $4 \mathrm{~cm}$ ) at $q$ of 0.44 , 9560.22 , and $0.044 \mathrm{~cm} \mathrm{~min}^{-1}$, respectively. All column experiments were performedat $\mathrm{pH} 7.5$ and IS $957=0.1 \mathrm{mM} \mathrm{KNO}_{3}$. The $\delta^{18} \mathrm{O}_{\mathrm{P}}$ value of the HANPs starting (influent) suspension was $10.70 \%$ 958 (shown by the dotted line). Standard deviation was calculated using $\delta^{18} \mathrm{O}_{\mathrm{P}}$ values obtained from 959 independent column experiments. The solid lines are the trends of isotope fractionation but not 960 fitting results.At $q=0.44 \mathrm{~cm} \mathrm{~min}^{-1}$, the O-isotopic composition in the retentate became gradually 961 heavier at greater depths (e.g., from 1 to $4 \mathrm{~cm}$ ). Similarly, for the retentate at $1 \mathrm{~cm}$ depth, the $962 \delta^{18} \mathrm{O}_{\mathrm{P}}$ value increased with decreasing $q$ (from 0.44 to $0.044 \mathrm{~cm} \mathrm{~min}^{-1}$ ). In contrast, with 963 decreasing $q$, the $\delta^{18} \mathrm{O}_{\mathrm{P}}$ value of effluent decreased. 